\title{
RESPONSABILIDADE SOCIAL EMPRESARIAL EM UMA INSTITUIÇÃO DE ENSINO SUPERIOR PARTICULAR: INSERÇÃO DA POPULAÇÃO IDOSA ATRAVÉS DA EXTENSÃO
}

\author{
Isadora Ciarini Ribeiro \\ Bacharel em Administração. Centro Universitário Metodista \\ Andrea Sander \\ Professor Mestre. Centro Universitário Metodista
}

\section{RESUMO}

A presente pesquisa foi realizada em uma Instituição de Ensino Superior Particular da cidade de Porto Alegre, com objetivo principal de verificar os desafios para a responsabilidade social empresarial em uma instituição de ensino superior particular a partir da inserção da população idosa através da extensão. Os objetivos específicos da pesquisa foram identificar como estão inseridas as questões de responsabilidade social empresarial na gestão da IES pesquisada;verificar a contribuição do programa para alcançar os objetivos da IES pesquisada, bem como para o desenvolvimento da população atendida pelo programa; e identificar os impactos da Universidade Adulto Maior (UAM) na qualidade de vida dos participantes. A pesquisa realizada foi de cunho quantitativo e qualitativo, respectivamente dirigida a dez discentes do Programa Universidade Adulto Maior do IPA e a Coordenadora do mesmo Programa, com apoio documental e observacional. A partir dos dados coletados observou-se que o Programa Universidade Adulto Maior possui significativa influência do movimento metodista, que permeia toda a gestão da IES pesquisada. Também se percebeu que os programas de responsabilidade social da IES são custeados pelo IPA, o que configura a responsabilidade social empresarial da instituição. Quanto a contribuição do programa para alcançar os objetivos da IES pesquisada, bem como para o desenvolvimento da população atendida pelo programa, se observou que a UAM contribui com os objetivos do Centro Universitário Metodista IPA, que são o fomentar a ciência e o conhecimento. Com relação aos ganhos dos alunos da UAM, 
foram destacados aumento da qualidade de vida; ganhos na parte cognitiva; mudança de perspectiva de vida; aquisição de informação; aumento da autoestima; e ter voz e ser ouvido no grupo, além do contato com novas tecnologias, que diminuem a distância entre essa faixa da população e as demais gerações.Constatou-se dos impactos da Universidade Adulto Maior (UAM) na qualidade de vida dos participantes as atividades que resultam em um sentimento de inclusão, de aprimoramento e desenvolvimento de habilidades, que contribuem com a saúde, com a prevenção de doenças e na qualidade de vida e na autonomia com as atividades cotidianas. Finalmente as pesquisadas são unânimes com relação ao bem estar no ambiente universitário. No que diz respeito ao objetivo principal da pesquisa, conclui-se que a Instituição pesquisada atende as questões de responsabilidade social, através do Programa de Extensão Universidade Adulto Maior, sendo precursora dessa modalidade de responsabilidade social empresarial entre as instituições de ensino superior particulares. O Programa UAM atende aos objetivos da instituição e ao desenvolvimento da população atendida por ele. Os discentes pesquisados atestaram a importância do Programa na contribuição para a qualidade de vida.

PALAVRAS-CHAVE: Responsabilidade Social Empresarial. Instituição de Ensino Superior Particular. População idosa. Extensão.

\section{CORPORATE SOCIAL RESPONSIBILITY IN A PARTICU- LAR HIGH SCHOOL INSTITUTION: INSERTION OF THE ELDERLY POPULATION THROUGH EXTENSION}

\section{ABSTRACT}

The present research was carried out in a Private Higher Education Institution of the city of Porto Alegre, with the main objective of verifying the challenges for corporate social responsibility in a private higher education institution from the insertion of the elderly population through extension. The specific objectives of the research were to identify how corporate social responsibility issues are addressed in the management of the HEI researched, to verify the contribution of the program to achieve the objectives of the HEI researched, as well as to the development of the population served by the program; and identify the impacts of the Adulto Maior University (UAM) on the participants' quality of life. The research carried out was of quantitative and qualitative nature, directed respectively to ten students of the Program Adulto Maior University of the IPA and the Coordinator of the same 
Program, with documentary and observational support. From the collected data it was observed that the Program Adulto Maior University has significant influence of the Methodist movement, which permeates all the management of the HEI surveyed. It was also realized that the social responsibility programs of the HEI are funded by the IPA, which constitutes the corporate social responsibility of the institution. As for the program's contribution to achieving the objectives of the HEI, as well as for the development of the population served by the program, it was observed that the UAM contributes to the objectives of the IPA Methodist University Center, which are to foster science and knowledge. With regard to the earnings of UAM students, an increase in the quality of life was highlighted; gains in the cognitive part; change of perspective of life; information acquisition; increased self-esteem; and have a voice and be heard in the group, in addition to the contact with new technologies, which reduce the distance between this population and the other generations. The impact of the Adulto Maior University (UAM) on the quality of life of the participants was analyzed which result in a sense of inclusion, improvement and development of abilities that contribute to health, disease prevention and quality of life and autonomy with daily activities. Finally, the researches are unanimous regarding the well being in the university environment. With regard to the main objective of the research, it is concluded that the Institution researched attends to the issues of social responsibility through the Extension Program Adulto Maior University, being a precursor of this modality of corporate social responsibility among private higher education institutions. The UAM Program meets the objectives of the institution and the development of the population served by it. The researched students testified to the importance of the Program in contributing to the quality of life.

KEYWORDS: Corporate Social Responsibility. Institution of Private Higher Education. Elderly population. Extension.

\section{INTRODUÇÃO}

O envelhecimento da população brasileira já é uma realidade, conforme estudos do Instituto Brasileiro de Geografia e Estatística (IBGE, 2015) o segmento da população que mais aumenta no Brasil é dos idosos, com taxas de crescimento de mais de $4 \%$ ao ano. Este crescimento é consequência da crescente queda das taxas de natalidade e fecundidade em 
todo o território brasileiro, somadas à diminuição das taxas de mortalidade em todas as faixas etárias.

A Europa enfrentou o fenômeno do envelhecimento de sua população antes do Brasil. Como alternativa para ocupar o tempo livre desse segmento populacional em expansão, foram criadas na França, nos anos 1960, as chamadas Universidades da Terceira Idade (UTI), que ofereciam atividades culturais e sociais a estes cidadãos (PEIXOTO, 1997). Nestes moldes, a primeira instituição de ensino superior brasileira a implementar o padrão europeu de Universidades Abertas foi, segundo Veras e Caldas (2004), a Universidade Federal de Santa Catarina, no ano de 1983.

Para as universidades federais as atividades desenvolvidas junto à população idosa estão ligadas à implementação das políticas públicas traçadas pelo Governo e executadas pelas instituições. Já para as instituições de ensino superior particulares a implementação de um programa de educação voltado para o público idoso passa pela competência da responsabilidade social empresarial (RSE), em que as empresas empregam seus recursos em prol da comunidade a fim de proporcionar o bem-estar, através de um relacionamento ético, conforme expresso por Melo Neto e Froes (2005).

A instituição de ensino superior particular pesquisada, Centro Universitário Metodista - IPA,é a primeira instituição brasileira a desenvolver um programa nesses moldes, em consonância com Ferreira (2013) que afirma que no Brasil os idosos são marginalizados e que a educação é uma forma prazerosa de ocupar a mente e o tempo, se colocando em sintonia com a atualidade, integrados a um grupo com os mesmos interesses, promovendo assim a qualidade de vida destes cidadãos.

Conforme as observações de Irigaray e Schneider (2008) as vantagens deste tipo de programa vão além, pois promovem a autoestima, a aquisição de novos conhecimentos, o preen- 
chimento do tempo com atividades prazerosas, levando a modificações significativas no sentido de vida. A inserção nas Universidades Abertas permite aos idosos o desenvolvimento e a realização pessoal, que, muitas vezes, em fases anteriores da vida não tiveram a oportunidade de fazer.

Em vista do exposto, esta pesquisa teve como objetivo verificar os desafios para a responsabilidade social empresarial em uma instituição de ensino superior particular a partir da inserção da população idosa através da extensão. Para alcançar este objetivo foram traçados objetivos três específicos: identificar como estão inseridas as questões de responsabilidade social empresarial na gestão da IES pesquisada; verificar a contribuição do programa para alcançar os objetivos da IES pesquisada, bem como para o desenvolvimento da população atendida pelo programa; e identificar os impactos da Universidade Adulto Maior (UAM) na qualidade de vida dos participantes.

A pesquisa se justifica frente a realidade brasileira, que conforme as projeções do IBGE (2015) "para os próximos 10 anos, haverá um incremento médio de mais de 1,0 milhão de idosos anualmente" (IBGE, 2015, p. 146). Acrescentando que esse segmento populacional em expansão, em geral, possui tempo livre e renda fixa, que pode ser preenchido com atividades que promovam a sua integração social. Com isso, as instituições de ensino podem ter seus espaços ocupados durante o período inverso das aulas, criando uma nova fonte de recursos. Além destas, de acordo com Nascimento (2014), o ingresso de pessoas da terceira idade nas IES traz diversas vantagens, como a interação da IES com a sociedade; o atendimento de múltiplas demandas nas IES, com o estabelecimento de metodologias interdisciplinares, auxiliando no trabalho conjunto entre diferentes departamentos do corpo docente, discente, juntamente com o grupo de técnicos; a realização de ações com elevado impacto social e custos reduzidos. Além 
disto, estes programas possibilitam à articulação da extensão com o ensino e a pesquisa nas IES, pois permitem que bolsistas e voluntários, além de discentes (estagiários) ampliem seus conhecimentos técnicos, desenvolvendo competências pessoais e técnicas ao trabalhar junto à população idosa.

\section{FUNDAMENTAÇÃO TEÓRICA}

A seguir serão apresentados tópicos essenciais para o entendimento trabalho desenvolvido, como o perfil da população de terceira idade o Brasil, qualidade de vida na maturidade, a gestão universitária e a responsabilidade social e extensão no ensino superior.

\section{Perfil da população de $3^{a}$ idade no Brasil}

Dados do Censo Demográfico 2010 apontam para o envelhecimento da população, que se acentuou nas duas últimas décadas, deixando claro o aumento da participação relativa da população "a partir do grupo de 25 a 29 anos de idade e o visível alargamento do topo da pirâmide etária, indicando o aumento da longevidade" (IBGE, 2010, p. 50). O Gráfico 1 apresenta a evolução da população residente urbana, por gênero, segundo os grupos de idade abrangendo um período de 50 anos, entre 1960 e 2010.

Já o Gráfico 2 apresenta um recorte, em um período de tempo menor, compreendendo o intervalo entre 1991 e 2010.

Em ambos os gráficos, indiferente ao período abarcado pela pesquisa, se percebe claramente que há uma tendência de envelhecimento da população brasileira, com a diminuição da base da pirâmide, a população mais jovem, em detrimento do topo, a população mais velha. Frente a isso, é de suma importância que esse segmento populacional receba cada vez mais atenção dos diversos setores da sociedade. $\mathrm{O}$ envelhecimento da população brasileira e mundial é um fenômeno demográfico que irá perdurar por gerações (CAMARANO, 2014). 
RESPONSABILIDADE SOCIAL EMPRESARIAL EM UMA

INSTITUIÇÃO DE ENSINO SUPERIOR PARTICULAR: INSERÇÃO

DA POPULAÇÃO IDOSA ATRAVÉS DA EXTENSÃO

Gráfico 1 - Composiçãa da população residente urbana, por sexo, segundo os grupos de idade - Brasil - 1960/2010

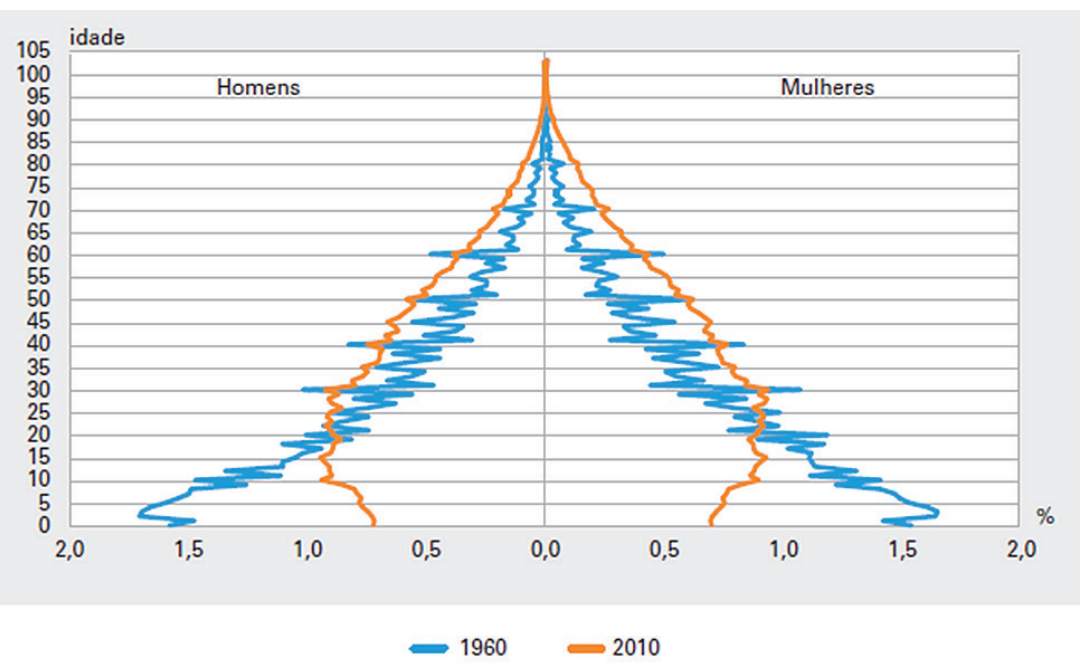

Fonte: IBGE, 2010, p. 50

Gráfico 2 - Composição da população residente urbana, por sexo, segundo os grupos de idade - Brasil - 1991/2010

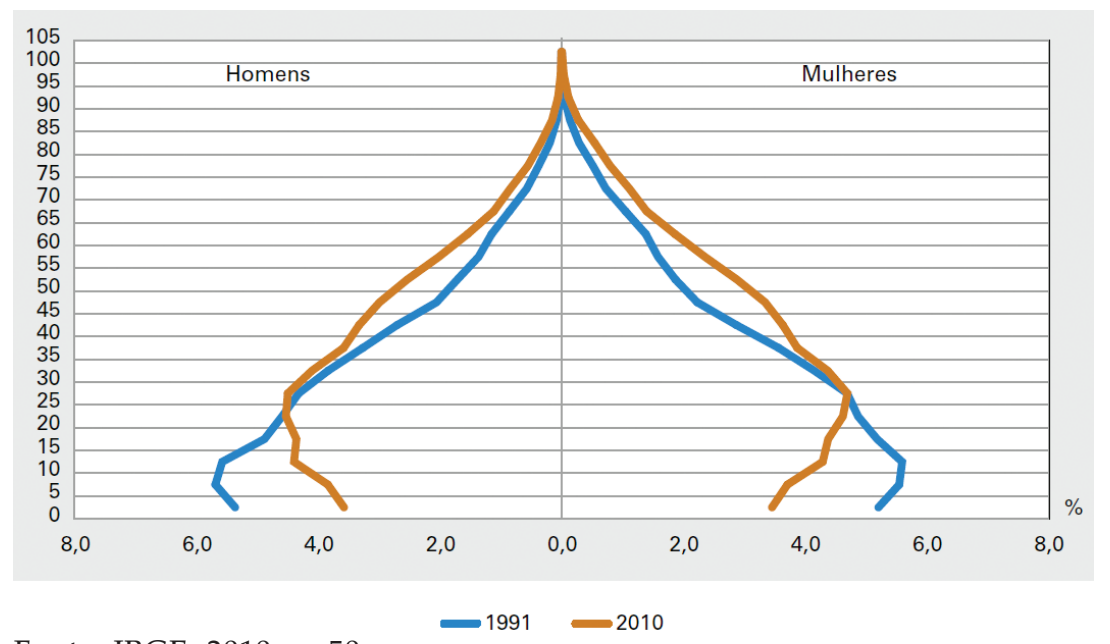

Fonte: IBGE, 2010, p. 50 
O critério para definição do grupo etário dos idosos do IBGE é aquele descrito pela Lei no . 10.741, de 01 de outubro de 2003 (BRASIL, 2003) e, "apesar da Organização das Nações Unidas - ONU não determinarem um critério único de idade, há concordância na idade de 60 anos ou mais para a população idosa". (IBGE, 2015, p. 15).

A Síntese de Indicadores Sociais do IBGE (2015) traz diversos dados com relação à população idosa no País. O primeiro deles aponta que os estados brasileiros com maior número de idosos são Rio de Janeiro e Rio Grande do Sul, onde uma em cada seis pessoas apresenta 60 anos ou mais de idade (IBGE, 2015). Fazendo um recorte dos dados do IBGE (2015), o Observatório da Cidade de Porto Alegre (ObservaPOA, 2015), lançou em parceria com a Prefeitura de Porto Alegre, a publicação As condições sociais da População Idosa de Porto Alegre, mostrando que a cidade é capital com a maior proporção de idosos, que representam 15,04\% da população, contra 14,89\% da população do Rio de Janeiro e 12,61\% de Belo Horizonte, respectivamente segunda e terceira cidades com mais idosos.

Há também que se destacar que ocorreu um crescimento significativo no grupo de pessoas com 80 anos ou mais de idade, que "passou de 1,2\%, em 2004, para 1,9\%, em 2014" (IBGE, 2015,p. 33). Ainda em 2014, grande parcela das pessoas com 60 anos ou mais de idade era composta por mulheres $(55,7 \%)$ e de cidadãs que se declararam brancas (52,6\%) (IBGE, 2015).

Camarano (2014) também aponta um aumento significativo do nível de escolaridade entre os indivíduos com idade superior a 60 anos no Brasil, bem como percebe uma melhoria nas condições de vida dos indivíduos desta faixa etária. Com a população idosa mais escolarizada, com melhores condições de consumo, é possível pensar em diversificação da oferta de atividades que promovam o bem-estar para além dos cuidados médicos para tratamentos de doenças. Estes dados estão 
em consonância com o observado pelo Instituto de Pesquisa Econômica Aplicada(IPEA, 2008):

Uma política de desenvolvimento deverá levar em conta esse tipo de situação. Não é outra, aliás, a motivação para a adoção de medidas que previnam os riscos de acidentes, violência e perda de condições de vida saudáveis observados nas sociedades mais avançadas. Os custos com gastos sociais podem ser compensados por menores gastos com tratamentos médicos ou de pessoal para cuidar dos doentes. (IPEA, 2008, p. 7).

Conforme observam o IPEA (2008) e Camarano (2014), as empresas precisam compreender que os gastos sociais com a população idosa são compartilhados por toda a sociedade. Neste contexto, todas as ações de responsabilidade social que beneficiam diretamente a população idosa, também beneficiam indiretamente toda a sociedade.

Uma vez traçado o panorama sobre a população idosa no país, o próximo item discute a qualidade de vida da população nesta faixa etária.

\section{Qualidade de vida na maturidade}

Conforme Terra (2001), o termo qualidade de vida ainda encontra dificuldades de conceituação devido à subjetividade do tema. Isso se dá porque depende de como um individuo define a sensação de bem-estar diante de variáveis que são diferentes para cada pessoa. Ainda assim existe um esforço para conceituar a qualidade de vida e um deles é definido como "capacidade de desempenhar atividades ou tarefas da vida diária, obtendo assim satisfação." (TERRA, 2001, p. 30).

Para os indivíduos maduros, a caracterização da qualidade de vida segue o sentido de ter autonomia para desenvolver atividades, porém esse conceito pode se expandir, segundo Neri (2012): 
A qualidade de vida na velhice é compreendida como um construto sociopsicológico e processual, que reflete formas socialmente valorizadas e continuamente emergentes de adaptação a condições de vida culturalmente reconhecidas que a sociedade oferece aos seus idosos. Observe-se que a definição se refere a um processo (adaptação) e não a um resultado, meta desenvolvimental, ou estado ideal [...] o processo de adaptação é multidimensional. É emocional, no sentido de envolver habilidade de autorregulação para lidar com estressores. É cognitiva, no sentido de permitir solução de problemas. É comportamental no sentido de implicar desempenhos efetivos e competência social (NERI, 2012, p. 25).

A autora critica as pesquisas na área da velhice que buscam apenas estabelecer quais as "perdas e limitações associadas a essa fase da vida", e deixam de lado "o potencial de desenvolvimento inerente à maturidade." (NERI, 2012, p. 7).

Programas como o da Universidade Adulto Maior, que incluem em seu currículo disciplinas que não apenas retardam as perdas advindas da velhice, mas desenvolvem as capacidades dos indivíduos, vão ao encontro do entendimento de qualidade de vida para a população madura. Os objetivos do curso estão descritos na página da IES e são:

Inclusão Social do Idoso. Contexto histórico, econômico, político, cultural e tecnológico da contemporaneidade. Manutenção das habilidades e competências sociais e cognitivas do idoso de forma a fortalecer e criar novas redes e contatos sociais. Proporcionar a manutenção e/ou resgate do exercício de autonomia e cidadania. Constituir-se enquanto espaço de prevenção e promoção de saúde e qualidade de vida. Constituir-se numa oportunidade de consolidação dos pressupostos sociais e finalidades institucionais numa concepção de trabalho inter e transdisciplinar.(CENTRO UNIVERSITÁRIO METODISTA DO IPA, 2015, paginação irregular).

É possível que os idosos tenham boa qualidade de vida na medida em que fatores individuais e socioculturais são levados em consideração nas atividades dessas pessoas. (NERI, 2012). 
Para mensurar a qualidade de vida dos idosos, critérios de avaliação precisam ser estabelecidos, conforme destaca Neri (2012):

Avaliar a qualidade de vida na velhice implica na adoção de múltiplos critérios de natureza biológica, psicológica e socioestrutural. Vários elementos são apontados como determinantes ou indicadores de bem-estar na velhice: longevidade, saúde biológica, saúde mental, satisfação, controle cognitivo, competência social, produtividade, atividade, eficácia cognitiva, status social, renda, continuidade de papeis familiares e ocupacionais, e continuidade de relações informais em grupos primários (principalmente rede de amigos). (NERI, 2012, p. 10).

Aqui se destaca que a rede de amigos citada por Neri (2010) pode ser inclusive digital, pois Cardoso et al. (2014), relatam que estes amigos podem ser resultantes da inclusão digital, uma vez vencidas as dificuldades com a tecnologia, associada ao fato de que os idosos viveram a maior parte de suas vidas sem esta ferramenta, sendo importante remover esta dificuldade para que os idosos descubram os benefícios que a utilização da tecnologia pode trazer às suas vidas.

Vieira e Santarosa (2009) em uma pesquisa com 19 idosos de um curso de informática apontam 13 categorias motivacionais para que estes indivíduos se interessem pela informática e na utilização de tecnologias como o computador e a Internet, sendo que dentre estas as autoras destacam quatro grandes grupos de interesse:

(1) necessidade de crescimento pessoal no âmbito do aprender e do sentir-se capaz de aprender e com isso, participar de uma sociedade cada vez mais tecnológica; (2) necessidade de interação com o outro, seja pela utilização das ferramentas de comunicação suportadas pela Internet, seja pelo contato com colegas do curso de informática, ou ainda pela possibilidade de fazer-se presente em situações de uso da tecnologia junto de familiares; (3) possibilidade de satisfação pessoal ao realizar atividades como passatempos e jogos e com isso, manter o cérebro em atividade ou sentir-se menos solitário; (4) necessidade utilitária, relacionada a aspectos práticos como realização de compras

ReMAS • Revista Metodista de Administração do Sul, v. 2, N. 2, 2017 
e orçamentos pela Internet. (VIEIRA; SANTAROSA, 2009, paginação irregular).

Ainda de acordo com Vieira e Santarosa (2009) a inclusão digital do idoso cumpre um importante papel social, pois as declarações dos pesquisados remetem desde a atualização pessoal em temas do mundo contemporâneo, até mesmo a vencer a solidão da velhice, este aspecto maior entre as mulheres pesquisadas e a aproximação com as gerações mais novas da família.

Alencar (2013), em pesquisa com 235 idosos, participantes da Universidade Aberta a Terceira Idade (UnATI), programa da Pró-Reitoria de Extensão da Universidade Federal de Pernambuco, abordando aspectos da sexualidade na terceira idade, destaca que a qualidade de vida nesta faixa etária pode ser entendida como:

\begin{abstract}
À medida que as pessoas envelhecem, a qualidade de vida se relaciona, principalmente, pela capacidade de manter a autonomia e a independência, implica habilidade que o idoso possui em se adaptar às limitações físicas, sociais e emocionais, buscando serenidade e satisfação na vida, mesmo em idade avançada. Estigmas sobre o envelhecimento estão associados à perda, doença e incapacidade, reforçando aspecto negativo desse processo, e quando se discute sobre a sexualidade do idoso, mitos e preconceitos ainda surgem na delimitação de uma fase de assexualidade. (ALENCAR, 2013, p. 16)
\end{abstract}

É fato que a velhice impõe certas perdas aos indivíduos, porém os idosos não passam a ser pessoas sem condições de desenvolvimento, como muitos acreditam. Outro pensamento difundido, porém falso é o de ser impossível envelhecer sem ter doenças. Sobre o tema Neri (2012, p. 31) destaca que "velhice não é sinônimo de doença. São os incidentes patológicos que produzem um organismo qualitativamente diferente na velhice, e não o envelhecimento, muito menos por causa da passagem 
do tempo". Portanto "a qualidade de vida na velhice não é um atributo pessoal, mas sim o resultado de um processo contínuo de mudanças no individuo e na unidade sociocultural em que se desenrola a sua história pessoal" (NERI, 2012, p. 25).

Roratto e Vieira (2011) destacam o surgimento de um novo velho, que deseja participar, opinar, ser feliz e viver, produto da evolução da medicina, que com tratamentos e ações preventivas contribuem para o aumento da expectativa de vida. Entretanto a autoras destacam, que este indivíduo encontra uma sociedade ligada às antigas concepções e tradições, que "não está totalmente preparada para lidar com essas pessoas, pois, mesmo diante desta realidade de envelhecimento populacional, são poucas as iniciativas sociais oferecidas ao desenvolvimento dos idosos." (RORATTO; VIEIRA, 2011, p. 2). As autoras ainda advertem que a sociedade pós-moderna tem contornos excludentes para todos, e em particular com os indivíduos com dificuldades para lidar com as mudanças inerentes a arte de viver.

\section{Gestão Universitária}

De acordo com Zainko e Pinto (2013) a administração de uma IES não se faz apenas com a organização dos recursos já existentes, mas também com a criação de relações sociais, políticas, culturais e pedagógicas. Apesar disso, as autoras reconhecem que o modelo gerencial empresarial de busca pela flexibilidade, rapidez, eficácia, eficiência e produtividade tem contribuído com a gestão educativa no sentido de trazer modernidade para esse tipo de administração. Entretanto, Zainko e Pinto (2013) fazem uma crítica, que recai no modelo verticalizado que concentra o poder de decisão nas mãos do diretor ou gestor das instituições de ensino. As autoras defendem que a qualidade do ensino depende de uma administração mais aberta, que conte com a participação da comunidade, tanto nas decisões, como na responsabilidade pelos resultados. 
Sobre os instrumentos de gestão do ensino superior, Zainko e Pinto (2013) destacam o plano de desenvolvimento institucional (PDI), previsto implicitamente nas Leis de Diretrizes e Bases do Ensino Nacional. A Lei não traz o modelo de planejamento, nem define como o mesmo deve ser elaborado, porém, a existência da avaliação institucional implica no processo a elaboração de um plano de acompanhamento. Neste sentido, cabe ao Governo Federal articular-se junto aos poderes estaduais e municipais a fim de garantir a existência de um processo avaliativo de todas as instituições de ensino superior no País.

Para Colombo (2013), a avaliação institucional das IES é um instrumento de gestão, pois pode auxiliar a dar o rumo estratégico, em quesitos alinhamento de missão, visão e valores, visto que, quando seu resultado é positivo, desencadeia um marketing favorável para a IES, ao atrair mais alunos e atenção do mercado. A autora ainda explicita que a gestão das IES se dá de maneira diferente do que no meio empresarial, devido a algumas particularidades que devem ser levadas em consideração quando for desenvolvida a estratégia de gestão, precedida por diagnósticos.

O Sistema Nacional de Avaliação da Educação Superior (SINAES), através das avaliações periódicas que desenvolve junto às IES, tanto nas auto-avaliações, quanto nas avaliações externas, têm como um de seus objetivos "promover a responsabilidade social das IES, respeitando a identidade institucional e a autonomia" (INEP, 2015, paginação irregular), pois um dos quesitos avaliados é justamente o de responsabilidade social desenvolvida pelas instituições. O entendimento é de que o SINAES auxilia as instituições de ensino a se orientarem para melhorar os aspectos organizacionais, acadêmicos e também sociais. (INEP, 2015).

A IES pesquisada faz parte do sistema educacional metodista que, segundo o Conselho Geral das Instituições Me- 
RESPONSABILIDADE SOCIAL EMPRESARIAL EM UMA

INSTITUIÇÃO DE ENSINO SUPERIOR PARTICULAR: INSERÇÃO

DA POPULAÇÃO IDOSA ATRAVÉS DA EXTENSÃO

todista de Ensino(COGEIME, 1999, p. 9) “a estrutura jurídica e administrativa das instituições metodistas está baseada nas mantenedoras, com vínculos de subordinação às regiões eclesiásticas ou à área geral".As IES do sistema educacional metodista são geridas pelos órgãos superiores que são os Conselhos Diretores, os Conselhos de Direção e as Diretorias Gerais, e seu quadro profissional é composto basicamente por pastores, teólogos, docentes e profissionais liberais.

Responsabilidade Social e Extensão no Ensino Superior.

Ao longo do tempo, o termo responsabilidade social empresarial evoluiu, bem como as ações desenvolvidas pelas empresas. Onde antes havia um esforço não coordenado e não mensurado, atualmente há "o uso sinérgico e mutuamente benéfico de competências básicas e recursos organizacionais, utilizados para atender às necessidades dos principais stakeholders em benefício da instituição e da sociedade" (FERRELL; FRAEDRICH; FERREL, 2001, p.85). A esse alinhamento das estratégias empresariais com os interesses da comunidade diretamente ligada a ela se denomina filantropia estratégica. Alessio (2008, p. 69) destaca os benefícios desse posicionamento estratégico, como "uma melhor otimização dos recursos e maior efetividade nas ações".

Apesar de ser uma discussão nova no meio acadêmico, já é possível encontrar pesquisas na área de Responsabilidade Superior Universitária, que conforme Bolan e Motta (2007, p. 205) "se por um lado é clara a natureza da RS na governança das instituições de ensino enquanto empresas, por outro, seu significado para a tríplice função universitária de ensino, pesquisa e extensão ainda é motivo de discussão". Também fazem uma diferenciação dos papéis das IES: o primeiro enquanto empresa; e o segundo enquanto instituição de ensino, afirmando que o segundo papel já está consolidado como

ReMAS - Revista Metodista de Administração do Sul, v. 2, N. 2, 2017 
responsável socialmente, enquanto o primeiro ainda precisa de uma maior ponderação.

Nesse sentido, se faz necessária uma reflexão sobre o ensino superior enquanto negócio, pois as IES particulares têm, mesmo aquelas sem fins lucrativos, que prezar por uma gestão ética, baseada em valores e por um relacionamento transparente com seus stakeholders. (BOLAN; MOTTA, 2007).

A oferta de serviços à comunidade através da extensão é uma realidade presente na gestão das IES e não é diferente com a IES pesquisada. Em sua apresentação, a Pró-Reitoria deixa clara essa visão de que

As ações extensionistas se desenvolvem, buscando através de parcerias com diversos segmentos da sociedade, atender as demandas sociais, a fim de intervir de forma positiva na vida dos cidadãos. Por ser uma instituição confessional fortemente comprometida com a missão da Igreja Metodista, busca expandir suas práticas e ações comunitárias às populações mais carentes da sociedade.[...] A Extensão como um espaço privilegiado, proporciona dentro do universo acadêmico superior, que os futuros profissionais sejam dotados de uma consciência cidadã com competências para enfrentar o mercado de trabalho, mas com valores éticos e postura crítica diante das contrariedades e subjetividades de um sistema perverso de exclusão (CENTRO UNIVERSITÁRIO METODISTA IPA, 2015, paginação irregular).

A visão apresentada vai ao encontro do que Bolan e Motta (2007, p. 206) definem como responsabilidade social em uma IES, em que uma IES responsável socialmente traz para a academia os problemas da sociedade, criando um "ambiente que fomenta a formação de lideranças, que propõe soluções, intervenções, discussões e tecnologias que contribuem para que a própria sociedade possa superar esses problemas".

\section{METODOLOGIA}

Esta pesquisa teve como objetivo verificar os desafios para a responsabilidade social empresarial em uma instituição de 
ensino superior particular da cidade de Porto Alegre, a partir da inserção da população idosa através da participação em um curso de extensão planejado e desenvolvido para essa faixa etária da população. Por se tratar de um tema ainda pouco explorado, sendo a instituição pesquisada a primeira no país a desenvolver um curso nesses moldes, a pesquisa foi caracterizada como exploratória que, segundo Cervo e Bervian (2002, p. 69) "têm por objetivo familiarizar-se com o fenômeno ou obter nova percepção do mesmo e descobrir novas ideias". Para a abordagem do problema foi escolhida a metodologia mista, tanto qualitativa, quanto quantitativa, e também documental e observacional, devido caracterização da pesquisa como exploratória, pois segundo Fonseca (2002, p. 20) “a utilização conjunta da pesquisa qualitativa e quantitativa permite recolher mais informações do que se poderia conseguir isoladamente". Cabe ressaltar que a pesquisa mista também atendeu aos dois públicos que foram pesquisados: a coordenação do programa pesquisado, em uma abordagem qualitativa, através de entrevista com perguntas abertas, baseada em roteiro de perguntas abertas; e os alunos do programa, numa abordagem quantitativa, com coleta de dados baseado em questionário com perguntas abertas e fechadas, nestas últimas se utilizou a escala gradual do tipo Likert, conforme as orientações de Vieira (2009).

No que se refere aos procedimentos caracterizou-se a mesma como um estudo de caso, que como destaca Yin (2010) é metodologia utilizada a partir do desejo de compreensão dos fenômenos sociais complexos, possibilitando aos pesquisadores a retenção holística e significativa das características de eventos reais, sendo utilizado em muitos casos para contribuir ao conhecimento de fenômenos individuais, de grupos, de organizações, de origem social, políticos, entre outros.

A pesquisa foi realizada na cidade de Porto Alegre, no Centro Universitário Metodista IPA, sendo e que, perante as 
características deste trabalho de conclusão de curso, a autora submeteu a pesquisa ao Comitê de Ética em Pesquisa, sendo autorizada com Certificado de Apresentação para Apreciação Ética (CAAE) número 67784316.1.0000.5308. A coleta de dados qualitativa compreendeu a entrevista com a Coordenadora do Programa Universidade Adulto Maior, a fim de extrair sua percepção sobre o Programa. A coleta quantitativa, ocorreu com os discentes do Programa de Extensão Universidade do Adulto Maior (UAM), que, segundo a Coordenação da UAM compõe-se de 130 alunos matriculados, que estudam no turno da tarde. A pesquisadora teve acesso aos pesquisados, conforme a autorização da Coordenadora do Programa Universidade Adulto Maior do Centro Universitário Metodista IPA, exclusivamente aos alunos presentes nas turmas da tarde, do dia primeiro de junho de 2017. Nesta ocasião havia 10 alunas presentes, divididas em duas turmas: uma com três discentes e outra com sete alunas. Concomitante a coleta quantitativa ocorreu a observação, quando a pesquisadora entrou em contato com os idosos pesquisados em seu ambiente de sala de aula e durante duas horas coletou as respostas e conversou livremente com as pesquisadas, já que contou com a ajuda de uma colega para distribuir e recolher os questionários.

Como a pesquisa foi de caráter misto, qualitativa e quantitativa, foi necessária a utilização de mais de uma técnica de análise de dados. Para a pesquisa quantitativa houve a tabulação dos dados obtidos através dos questionários em que as perguntas fechadas foram agrupadas a fim de gerar dados numéricos e após foram analisados através de gráfico de setores e barras. Para análise de dados qualitativos, o primeiro passo é, segundo Klein et. al. (2015), fazer a sintetize dos dados obtidos, que, geralmente nesse tipo de pesquisa, se tornam abundantes. Como critério para manter ou descartar um determinado dado, as autoras identificam a necessidade 
de os mesmos estarem ligados ou não ao tema da pesquisa. A categorização dos dados por tipos de resposta referentes às variáveis pesquisadas e o destaque dos dados obtidos mais significativos para a investigação também fazem parte desta etapa de análise, e foi a metodologia aqui empregada, onde as respostas foram organizadas obedecendo os objetivos específicos previamente traçados.

\section{RESULTADOS E DISCUSSÃO DA PESQUISA}

A presente pesquisa foi realizada no Centro Universitário Metodista IPA, Instituição de ensino superior localizada na Rua Coronel Joaquim Pedro Salgado, 80, na cidade de Porto Alegre, no estado do Rio Grande do Sul, sendo os dados aqui apresentados foram obtidos a partir da análise documental no site da IES (http://ipametodista.edu.br, 2017).

O IPA é uma associação de caráter civil, que tem sua confessionalidade ligada ao movimento religioso denominado Metodismo e cujos objetivos estão elencados como sendo educacionais, culturais, de assistência social e filantrópica (IPA, 2017). É também uma instituição credenciada pelo Ministério da Educação (MEC), estando enquadrada como Centro Universitário, e possui representatividade significativa em seu segmento na capital gaúcha.

O IPA faz parte da rede mundial de Instituições de Ensino Metodistas, composta por mais de 700 estabelecimentos ao redor do mundo que abrangem do ensino básico ao universitário. O Centro Universitário e suas unidades são geridos pela Direção Geral, que é integrada pelo Diretor Geral, Diretor Acadêmico e Diretor Administrativo (Tesoureiro). O desenvolvimento dos processos institucionais, administrativos e acadêmicos têm suas políticas, diretrizes e ações definidas pela Direção Geral e implementadas pelas gerências, assessorias e coordenadorias. 
O IPA desenvolve atividades no ensino superior, nas áreas de pós-graduação Lato Sensu e Stricto Sensu, oferecendo mais de 25 cursos de graduação, entre bacharelados e licenciaturas, tecnólogos e cursos de pós-graduação e mestrados.

As informações sobre a Universidade Adulto Maior são facilmente acessadas no site do Centro Universitário Metodista IPA, na opção Extensão. O site da UAM traz inúmeras informações, como a Estrutura do Programa; as disciplinas obrigatórias e as eletivas (oficinas) oferecidas; as informações sobre como e onde fazer as inscrições; além dos valores das mensalidades. Apresenta também diversas fotografias das atividades realizadas.

As disciplinas obrigatórias focam os aspectos relativos ao processo de envelhecimento, em suas diversas perspectivas, sendo elas: Enfoque Biológico, Enfoque Psicológico, Enfoque Histórico, Enfoque Sócio-Antropológico e Enfoque Espiritual. Já as disciplinas ou oficinas eletivas buscam complementar e inserir o idoso no mundo atual. São elas: Natação, Hidroginástica, Vivência Corporais, Pilates em Solo, Movimento, Ginástica, Oficina de Memória, Informática, Leitura e Literatura, Rádio, Coral, Reciclagem do Pensamento, Práticas Integrativas e Terapias Complementares, Fotografia, História da Arte e Moda Sustentável. Estas atividades são muito semelhantes às oferecidas por outros programas com a mesma proposta, de atender o idoso, como por exemplo, a desenvolvida pela Universidade para a Terceira Idade da Universidade Federal do Rio Grande do Sul (UNITI/UFRGS),projeto de extensão, de ensino e de pesquisa do Instituto de Psicologia da UFRGS, descrita por Irigaray e Schneider (2008). Também pode se citado o Grupo de Estudos da Terceira Idade (GETI)da Universidade do Estado de Santa Catarina (UDESC), ligado à extensão do Centro de Ciências da Saúde e do Esporte, conforme descrito por Mazo et al. (2014). Estes projetos de extensão têm respec- 
tivamente 17 e 25 anos de atividade e mostram o pioneirismo da Região Sul do Brasil na atenção ao idoso.

Outra rica fonte de informações sobre a UAM é a página do Facebook (https://www.facebook.com/uam.ipa/). Na página da UAM podem ser encontradas fotos e filmes das atividades cotidianas realizadas, como as aula, trabalhos finais, apresentações, viagens de estudo e trabalhos que são expostos no campus. A página também é utilizada para avisos dos professores aos alunos, para divulgar alguma atividade e até mesmo para noticiar o falecimento de algum dos participantes, fato que não é incomum nesta faixa etária. Na página também estão publicadas inúmeras declarações dos alunos, como por exemplo:

é o nosso segundo lar, é onde está a nossa família do coração. Amo muito! (DISCENTE UAM, 2016).

Eu sou suspeita em falar. Sou fã número 1 deste programa. Participo a 10 anos da UAM/IPA. É um presente em minha vida. Os professores são maravilhosos e a cumplicidade e amizade da turma me faz muito feliz. (DISCENTE UAM, 2015).

Estas declarações, entre outras tantas semelhantes, dão a dimensão do que o grupo representa para muitos dos participantes.

Para identificar como estão inseridas as questões de responsabilidade social gestão da IES pesquisada, buscou-se as respostas através da entrevista com a Coordenadora do Programa Universidade Adulto Maior. A entrevistada tem formação superior em Terapia Ocupacional, e exerce a profissão de Terapeuta Ocupacional, atualmente ocupando o cargo de Coordenadora do Programa Universidade Adulto Maior.Inicialmente se buscou conhecer como teve início o Programa Universidade do Adulto Maior, onde a entrevistada respondeu que: 
O Programa, neste formato, foi criado em 2003, mas a relação com os idosos é muito anterior, com o curso de Terapia Ocupacional do IPA. Em 1994 o curso de educação física criou um grupo de convivência para idosos, com foco em atividade físicas e sociais. A UAM tem um foco mais amplo, não apenas de cuidados com a saúde física, mas também de produção de conhecimento cientifico, conhecimentos dos próprios discentes sobre o envelhecimento, dentro de diferentes enfoques trabalhados pelo curso. O diferencial da UAM é que para o aluno se matricular, são obrigatórias as disciplinas de conhecimentos sobre o envelhecimentos que geram reflexão. (ENTREVISTADA, 2017)

Uma vez que o IPA é uma instituição de ensino confessional, baseando os seus princípios, objetivos e forma de atuação no Metodismo, se buscou compreender a influência do desse movimento religioso nos programas de responsabilidade social desenvolvidos pela Instituição. A entrevistada relatou que no seu entender a relação é íntima, pois o Metodismo tem o viés da diversidade, sendo o IPA a primeira instituição de ensino superior a receber alunos refugiados, com este intercâmbio financiado integralmente pela Instituição. A entrevistada também destacou o viés da inclusão e da inserção das minorias, como princípio presente no metodismo.

Ao se abordar a gestão da UAM, a entrevistada relatou que a gestão financeira do Programa Universidade Adulto Maior, ocorre como nos demais cursos do IPA, já que os discentes da UAM pagam uma mensalidade fixa no valor de $\mathrm{R} \$ 155,00$ (cento e cinqüenta e cinco reais) mensais, na data da pesquisa, sendo este valor destinado ao centro de custo do Programa. Entretanto a entrevistada não soube precisar se o Programa se auto sustenta ou se a instituição acrescenta um valor para seu custeio, já que os professores que lecionam na UAM recebem o mesmo valor de horas/aula do que nos cursos regulares da instituição.

Neste sentido se observa que, de acordo com o site do IPA a mensalidade do curso de graduação mais barato da Institui- 
ção, Filosofia, custa $\mathrm{R} \$ 801,00$ (oitocentos e um reais), sendo que a diferença entre a mensalidade da UAM e o do curso de Filosofia é significativo, de $\mathrm{R} \$ 645,00$ (seiscentos e quarenta e seis reais) à época da pesquisa (se multiplicado por seis meses, tempo do semestre a diferença chega a $\mathrm{R} \$ 3.870,00)$. Frente ao exposto, se entendeu que a IES assume parte do custeio com os alunos da UAM. Além disto, não se pode ignorar que muitas das atividades oferecidas correspondem aos cursos mais caros, como as diversas atividades físicas que fazem uso das dependências e equipamentos dos cursos de Fisioterapia e Educação Física, com mensalidades elevadas, respectivamente de $\mathrm{R} \$ 2.573,00$ (dois mil quinhentos e setenta e três reais) e $\mathrm{R} \$ 1.148,00$ (um mil cento e quarenta e oito reais), como revelou a pesquisa documental no site do IPA.

A entrevistada ainda ressaltou que não há qualquer ajuda governamental ou de parceiros externos para a manutenção da UAM, mas desatacou a parceria com a Associação Desportiva do IPA (ADIPA), para atividades físicas dos alunos da UAM, que são extensas e variadas, incluindo natação, hidroginástica, Pilates, entre outras.

Para identificar a contribuição do programa UAM para alcançar os objetivos da IES pesquisada, bem como para o desenvolvimento da população atendida pelo programa, foi questionado à Coordenadora da UAM os ganhos que a mesma percebe para o IPA, ao que a entrevistada respondeu que:

Para a instituição, o convívio com o adulto maior, a oportunidade de conhecer mais essa faixa etária e de aprendizagem de todos. (ENTREVISTADA, 2017).

Da mesma forma, foi questionado sobre os ganhos que a entrevistada percebe junto ao público da UAM, sendo que a Coordenadora relatou que estes são muitos, citando o aumento da qualidade de vida; ganhos na parte cognitiva; mudança

ReMas - Revista Metodista de Administração do Sul, v. 2, N. 2, 2017 
de perspectiva de vida; aquisição de informação; aumento da autoestima; e ter voz e ser ouvido no grupo. Além disto, a entrevistada ainda assinalou a conquista de novas amizades, que na maioria das vezes transcendem o espaço da sala de aula. Outro ponto destacado pela entrevistada e que poderia passar despercebido, mas que têm reflexo na vida dos participantes da UAM é a inserção nas redes sociais e os relacionamentos interpessoais. Estes dois últimos inserem o idoso no mundo virtual, muitas vezes diminuindo a distância entre eles e seus familiares e amigos, pois as aulas de informática, desenvolvidas em um contexto acolhedor, com colegas da mesma idade e com as mesmas dificuldades, derrubam as barreiras da inibição, permitindo que estes idosos vençam os limites impostos pela tecnologia.

Os ganhos apresentados, tanto para a IES quanto para os alunos da UAM, vão ao encontro da visão de Bolan e Motta (2007) sobre como se define a responsabilidade social empresarial em uma instituição de ensino superior, que aproxima a comunidade e seus problemas da academia, estimulando as discussões e criando soluções benéficas para todos os interessados. $\mathrm{O}$ meio acadêmico se enriquece através dessa troca, pois adquire insumos necessários a produção do conhecimento, objetivo das instituições de ensino. A comunidade ganha com o desenvolvimento que os programas sociais proporcionam, com a qualidade de vida dos indivíduos, com a sua inclusão na sociedade que muitas vezes deixam de lado a população idosa por não estar mais produzindo economicamente, sem perceber que existem outros tipos de contribuição que essas pessoas podem dar.

Ainda sobre a contribuição do UAM para o alcance dos objetivos do IPA, questionou-se a entrevista como ela compreendia esta essa questão. A Coordenadora da UAM esclareceu que, sob o seu ponto de vista, o Programa cumpre integralmente com seu papel social e acrescentou que: 
RESPONSABILIDADE SOCIAL EMPRESARIAL EM UMA

INSTITUIÇÃO DE ENSINO SUPERIOR PARTICULAR: INSERÇÃO

DA POPULAÇÃO IDOSA ATRAVÉS DA EXTENSÃO

O Programa não é filantrópico, é de desenvolvimento social. Também não é um programa de voluntariado, mesmo que esse ocorra ocasionalmente. Os professores são pagos para dar aula na UAM o mesmo valor que são pagos pelos demais cursos. (ENTREVISTADA,2017).

Esta visão de diferenciação entre filantropia e desenvolvimento social, principal propósito da responsabilidade social, converge com Melo Neto e Fores (2005) que fazem uma distinção entre programas sociais e ações comunitárias ou filantrópicas. Os programas sociais são empreendimentos gerenciados pela própria empresa, com uso de recursos próprios, que atendem um grupo de pessoas por ela delimitado, buscando o desenvolvimento social e trazendo um retorno para a empresa de melhoria na sua imagem perante a sociedade, como é o caso do Programa Universidade Adulto Maior. Já as ações comunitárias se dão através de parcerias com outras entidades, geralmente do Terceiro Setor, que recebem das empresas doações e que redistribuem para os públicos que se pretendem atingir. Assim, é possível observar, através da resposta da entrevistada, que a UAM cumpre com muitos dos requisitos de um programa de responsabilidade social, como destacam Melo Neto e Froes (2005), pois o Programa tem como sujeito da ação a empresa, no caso o IPA,como um todo e não apenas um indivíduo (no caso o empresário, representado aqui pelo papel da Reitora), empregando esforços e recursos em uma transformação da realidade atual, precária, para uma realidade com mais oportunidades.

Ao ser questionada sobre a forma de divulgação do Programa para novos alunos, a entrevistada relatou que não é feita nenhuma propaganda externa em mídias, apenas a divulgação pelo site da Instituição e na página do Facebook (respectivamente Figuras 1 e 2). A entrevistada ressalta que a maior propaganda é feita pelos próprios alunos que divulgam para seus conhecidos as vantagens de estudar na UAM

ReMAS - Revista Metodista de Administração do Sul, v. 2, N. 2, 2017 
e fazem com que outras pessoas se interessem, ao ponto de que em algumas atividades há lista de espera.

Sobre os impactos da UAM para o IPA, a entrevistada foi enfática, destacando que o Programa traz inúmeras contribuições à instituição, destacando entre eles:

A convivência intergeracional. Ganho de conhecimentos para estagiários da instituição, graduandos e para a própria academia. (ENTREVISTADA,2017).

A percepção da Coordenadora do Programa UAM é corroborada por Nascimento (2014), quando o autor destaca que as ações de inserção do idoso nas IES não repercutem unicamente sobre esse público, seus reflexos ultrapassam os limites das IES, transformando paradigmas sociais, levando à educação da comunidade acadêmica local, uma vez que aproxima os idosos às gerações mais jovens, contribuindo com um intercâmbio, no sentido mais amplo da palavra, com alunos de graduação, docentes e técnicos da IES. Esta troca é fundamental, pois inibe e derruba estereótipos com relação à Terceira Idade, aspecto crucial em uma instituição de ensino onde muitos dos cursos estão voltados à área da saúde, como Fisioterapia, Fonoaudiologia e Nutrição, preparando os discentes para este contato.

Mazo et al. (2014) também deixam claro os ganhos que a academia têm com programas desta natureza expondo que os mesmos permitem a formação de recursos humanos capacitados para lidar com esse público, conforme a área profissional, proporcionando um estímulo a profissionais envolvidos nestes projetos.

A entrevistada foi ainda questionada sobre os ganhos na qualidade de vida dos alunos da UAM, visto que este é o escopo de desenvolvimento social do Programa mantido pela Instituição, ao que ela apontou os seguintes ganhos: 
RESPONSABILIDADE SOCIAL EMPRESARIAL EM UMA

INSTITUIÇÃO DE ENSINO SUPERIOR PARTICULAR: INSERÇÃO

DA POPULAÇÃO IDOSA ATRAVÉS DA EXTENSÃO

Melhoria na qualidade de vida, manutenção das habilidades cognitivas, desenvolvimento de novas capacidades, convívio social, aprender coisas novas. (ENTREVISTADA, 2017).

Um diferencial dos programas de responsabilidade social é que estes buscam mensurar resultados a fim de se aperfeiçoarem e gerarem melhores resultados para as empresas e também para a população atendida. Suas ações se dão de forma planejada, estrutura, mensurada e visam o desenvolvimento integral do ser humano, conforme expõem Melo Neto e Froes (2005). Neste contexto, ainda se pode destacar Neri (2012) que desenvolve indicadores para medir a qualidade de vida dos idosos. De acordo com este autor, avaliar a qualidade de vida na velhice implica na adoção de múltiplos critérios de natureza biológica, psicológica e sócio estrutural. Neri (2012) cita vários elementos determinantes ou indicadores de bem-estar na velhice: longevidade, saúde biológica, saúde mental, satisfação, controle cognitivo, competência social, produtividade, atividade, eficácia cognitiva, status social, renda, continuidade de papéis familiares e ocupacionais e continuidade de relações informais em grupos primários (principalmente rede de amigos).

Assim, para atender estas premissas, se buscou identificar os impactos da Universidade Adulto Maior (UAM) na qualidade de vida dos participantes. Infelizmente, por limitações da pesquisa, o número de respondentes ficou restrito a apenas 10 discentes, que no momento da coleta de dados, estavam finalizando a aula quando a pesquisadora foi introduzida na sala de aula acompanhada por uma bolsista que auxilia a Coordenadora da UAM. Apesar disso, todas concordaram em esperar para responder a pesquisa, demonstrando interesse, ao fazerem perguntas sobre o curso da autora e sobre a pesquisa. Quando tinham alguma dúvida, logo questionavam. Ao fim da coleta, desejaram boa sorte na conclusão e apresentação do

ReMas - Revista Metodista de Administração do Sul, v. 2, N. 2, 2017 
presente trabalho. Todas estavam arrumadas e trocavam ideias entre si, se mostrando integradas e comunicativas.

As primeiras oito perguntas objetivaram traçar um perfil socioeconômico e demográfico do público atendido pelo Programa.Os resultados obtidos apontaram que a totalidade das pesquisadas é do gênero feminino, e predomina a faixa etária entre os 70 e 74 anos, com quatro respondentes; seguida das faixas entre 60 e 64 e 65 e 69 anos, cada uma delas com duas discentes; as idades entre 75 e 79 anos e 80 a 84 anos contam com uma discente cada uma, como pode ser observado no Gráfico 3.

Estes dados, embora devam ser encarados com alguma reserva, em função do número restrito de pesquisados, vêm ao encontro das estatísticas do IBGE (2015), em que a maioria da população idosa $(55,7 \%)$ é composta por indivíduos do gênero feminino. Se considerada apenas a população da Capital, o ObservaPOA (2015) indica que entre os idosos residentes na cidade em 2010, 62,25\% eram mulheres e 37,75\% eram homens. Em conformidade ao encontrado, Irigaraye Schneider (2008) descrevem, em um programa semelhante desenvolvido na Universidade Federal do rio Grande do Sul, que recebe em média 150 idosos por semestre, o número de homens participantes nunca ultrapassou os $5 \%$.

Gráfico 3 - Faixa etária das discentes da UAM

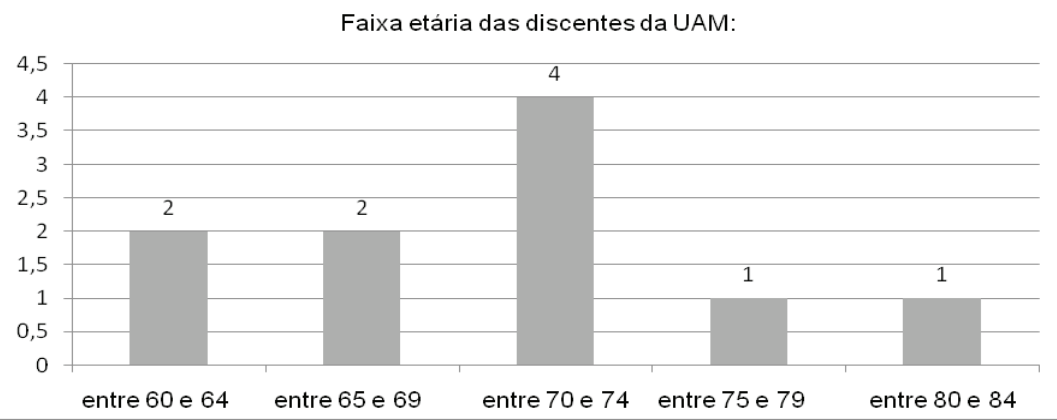

Fonte: dados da pesquisa, 2017 
RESPONSABILIDADE SOCIAL EMPRESARIAL EM UMA

INSTITUIÇÃO DE ENSINO SUPERIOR PARTICULAR: INSERÇÃO

DA POPULAÇÃO IDOSA ATRAVÉS DA EXTENSÃO

Outro dado exposto pelo IBGE (2015) é que os profissionais liberais adiam a aposentadoria para depois dos 70 anos, somando $42,3 \%$ o percentual dos que trabalham até os 70 anos. Foi observado todas as dez respondentes tinham curso superior, sendo que uma delas tinha mestrado, corroborando a observação de Camarano (2014) que identificou um aumento significativo da escolaridade dos idosos no Brasil. O Quadro 2 expõem os dados obtidos quanto a profissão das discentes, se faz a ressaltava de que nem todas as pesquisadas responderam esta questão.

Quadro 2 - Profissão das discentes da UAM

\begin{tabular}{|l|l|}
\hline \multicolumn{2}{|l|}{ Profissão das discentes da UAM } \\
\hline Participante A & Professora aposentada \\
\hline Participante B & Aposentada \\
\hline Participante C & Advogada \\
\hline Participante D & Cirurgiã dentista \\
\hline Participante E & Engenheira e advogada \\
\hline Participante F & Professora de matemática aposentada \\
\hline
\end{tabular}

Fonte: dados da pesquisa, 2017

Quanto a escolaridade das pesquisadas, a pesquisa diverge dos dados do IBGE (2015) e do recorte destes dados realizado pelo ObservaPOA (2015), pois de acordo com esta entidade, o nível de escolaridade é baixo entre os idosos que vivem em Porto Alegre, pois em 2010, 41,30\% dos cidadãos com mais de 60 anos eram sem instrução ou tinham apenas o ensino fundamental incompleto. O estudo mostrou que $22,20 \%$ dos idosos tinham ensino médio completo e superior incompleto, $20,18 \%$ apresentavam superior completo e $16,11 \%$ possuíam ensino fundamental completo e médio incompleto. Porém estas diferenças podem ser explicadas pelo perfil da atividade oferecida pela UAM, pois retornam a instituição de ensino superior aquelas pessoas que já se beneficiaram dele no passado e têm uma familiaridade com o ambiente universitário,

ReMas - Revista Metodista de Administração do Sul, v. 2, N. 2, 2017 
aliado a renda superior, como será observado no resultado do próximo questionamento.

Cabe ressaltar que o local onde se instala o campus, um bairro de classe média, e mesmo o estado onde está instalada a UAM, um dos estados brasileiros onde a escolaridade da população é mais elevada, certamente refletem nos resultados, pois estes diferem em parte dos obtidos por Alencar (2013), em pesquisa com 235 idosos, participantes da Universidade Aberta a Terceira Idade (UnATI), programa da Pró-Reitoria de Extensão da Universidade Federal de Pernambuco, onde o nível de escolaridade de nove anos ou mais de anos de estudos correspondeu a $64,7 \%$, cabendo destacar que $3,8 \%$ não tinham escolaridade, dos quais todos eram o sexo feminino.

$\mathrm{Na}$ sequência, para traçar um perfil socioeconômico do público da UAM, foi questionado às discentes sobre a sua renda, com os resultados obtidos expostos no Gráfico 4, onde, com relação à renda, e seguindo a tendência mencionada por Camarano (2014), de aumento nas condições de consumo da população idosa, a renda da população atendida pelo programa social da UAM ultrapassa a de dois salários mínimos.

Gráfico 4 - Renda das discentes da UAM

\section{Renda das discentes da UAM}

Acima de vinte salários mínimos (R\$ $15.760,01$ ou mais)

Entre dez e vinte salários mínimos (De R\$ $7.880,01$ a $\mathrm{R} \$ 15.760,00)$

Entre quatro e dez salários mínimos (De R\$ $3.152,01$ a $R \$ 7.880,00)$

Entre dois e quatro salários mínimos (De $\mathrm{R} \$ 1.576,01$ a $\mathrm{R} \$ 3.152,00$ )

Fonte: dados da pesquisa, 2017

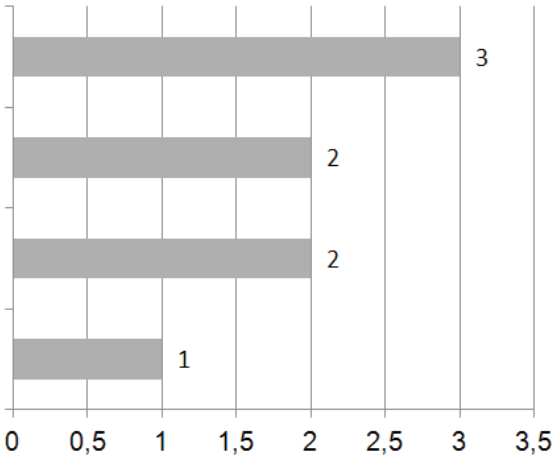


RESPONSABILIDADE SOCIAL EMPRESARIAL EM UMA

INSTITUIÇÃO DE ENSINO SUPERIOR PARTICULAR: INSERÇÃO

DA POPULAÇÃO IDOSA ATRAVÉS DA EXTENSÃO

Novamente aqui se pode traçar um paralelo aos dados encontrados no relatório As condições sociais da população Idosa de Porto Alegre (ObservaPOA, 2015), onde maioria dos idosos (62,54\%) afirmou ser responsável pelo domicílio onde vivia e que o rendimento médio do idoso em Porto Alegre é $27,72 \%$ superior ao das pessoas com menos de 60 anos. Nesta mesma pesquisa, os moradores com menos de 60 anos da cidade em 2010 tinham um rendimento médio de $\mathrm{R} \$ 2.422,70$ frente a um rendimento de $\mathrm{R} \$ 3.094,19$ dos idosos, que resulta em aproximadamente seis salários mínimos de acordo com o valor vigente em 2010 , que era de $\mathrm{R} \$ 510,00$, se alinhando ao aqui encontrado.

Com relação ao local da residência, se observou que a maioria das discentes da UAM mora na zona oeste da capital, somando cinco pesquisadas; frente a três da zona leste; e uma no centro e outra na zona norte. A publicação do ObservaPOA (2015) mostra que a região do orçamento participativo com o maior número de pessoas com mais de 60 anos é o Centro, somando $21,72 \%$ da população, seguida pela região Noroeste, 19,71\% da população da Capital. Estes dados de uma forma geral convergem com os aqui encontrados.

Quando questionadas sobre como conheceram a UAM, as discentes foram unânimes ao afirmar que chegara a UAM através de indicação por amigos e familiares que frequentam ou frequentaram a Instituição. O dado não causa surpresa, pois como a Coordenadora do Programa já havia revelado na pesquisa qualitativa, o IPA não faz marketing sobre a UAM, se limitando à divulgação na página do Facebook e no site da Instituição. Adicionalmente outros trabalhos de conclusão de curso já sinalizaram que os discentes dos diversos cursos regulares do IPA chegam à IES a partir de indicação de familiares e amigos.

O próximo passo da pesquisa foi compreender de que forma as atividades desenvolvidas na UAM impactam na

ReMAS - Revista Metodista de Administração do Sul, v. 2, N. 2, 2017 
qualidade de vida destas mulheres, para isto foram realizadas questões abordando os diversos aspectos do cotidiano da UAM e os sentimentos destas idosas. Com esta finalidade, a primeira questão buscou verificar a percepção das discentes quanto aos seus relacionamentos, onde se observou que a totalidade das discentes reconhece os reflexos da UAM neste aspecto, concordando pelo menos parcialmente, que após o ingresso na UAM desenvolveu e manteve mais relacionamentos. O aumento da rede de contatos está muito relacionado às atividades em grupo, desenvolvidas entre as idosas, como viagens, o coral, exposições, atividades físicas entre outras, ao que Irigaray e Schneider (2008) destacam que estas atividades grupais, quando realizadas com pessoas da mesma geração, favorecem a boa qualidade de vida, já que possibilitam a vivência e a construção de significados comuns, conquistando novas amizades, obtendo suporte social, ajudando os idosos em condições normais e sob estresse.

Como forma de corroborar e até mesmo balizar a influência da UAM sobre os relacionamentos das discentes foram propostas outras duas assertivas semelhantes: Após iniciar seus estudos na UAM, conheci mais pessoas, mas não mantenho muitos relacionamentos e Após iniciar seus estudos na UAM, mantive meu quadro de relacionamentos inalterado, os resultados estão apresentados nos Gráficos 5 e 6 .

Os dados do Gráfico 5 mostram uma dicotomia entre as pesquisadas, já que o número de discentes que concorda com a assertiva é igual ao número de discentes que discorda, mas no Gráfico 6 se percebe o predomínio das respondentes que discordam que seu quadro de relacionamentos permaneceu inalterado após o ingresso na UAM, permitindo supor que o Programa abriu o leque de relacionamentos das participantes. 
RESPONSABILIDADE SOCIAL EMPRESARIAL EM UMA

INSTITUIÇÃO DE ENSINO SUPERIOR PARTICULAR: INSERÇÃO

DA POPULAÇÃO IDOSA ATRAVÉS DA EXTENSÃO

Gráfico 5 - Respostas da discentes da UAM frente a assertiva: Após iniciar seus estudos na UAM, conheci mais pessoas, mas não mantenho muitos relacionamentos

Após iniciar seus estudos na UAM, conheci mais pessoas, mas não mantenho muitos relacionamentos

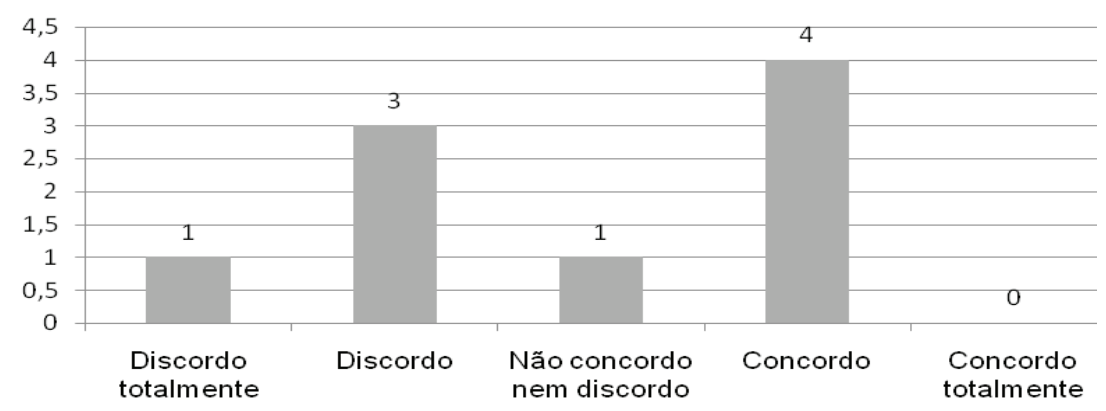

Fonte: dados da pesquisa, 2017

Gráfico 6 - Respostas da discentes da UAM frente a assertiva: Após iniciar seus estudos na UAM, mantive meu quadro de relacionamentos inalterado

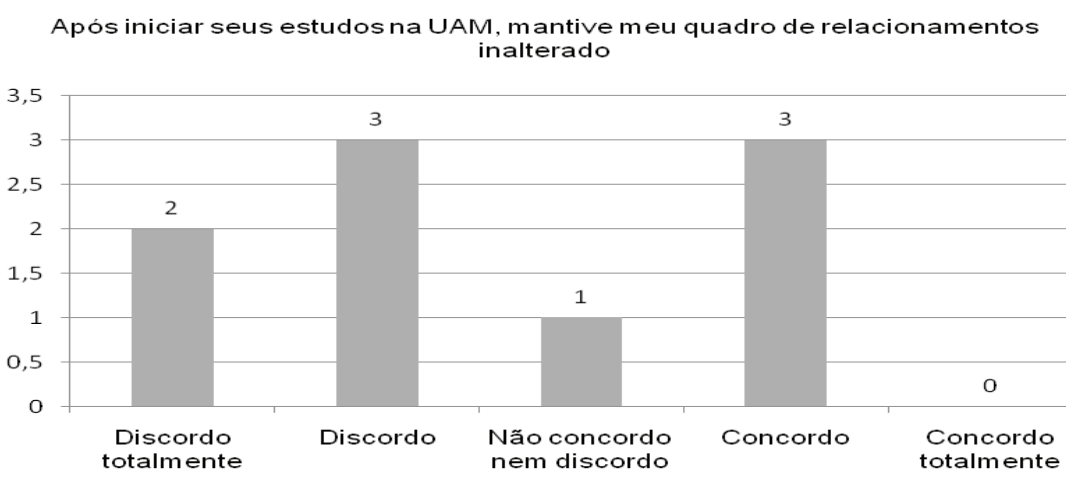

Fonte: dados da pesquisa, 2017

Na sequencia se averiguou como a participação na UAM impacta no uso das tecnologias digitais, particularmente o computador, a internet e as redes sociais, sendo que os resultados estão expostos nos Gráficos 7, 8, 9 e 10. Num primeiro 
momento foi verificada a adaptação das discentes com relação aos sistemas operacionais mais frequentes nos computadores, como o Windows e o Linux (GRÁFICO 7), ao que se observa que seis discentes concordam, pelo menos parcialmente, que a UAM impactou positivamente este aspecto, frente a duas discentes que discordam; uma discente ficou neutra.

Gráfico 7 - Respostas da discentes da UAM frente a assertiva: Após iniciar seus estudos na UAM, me sinto adaptado aos sistemas operacionais dos computadores, como Windows e Linux

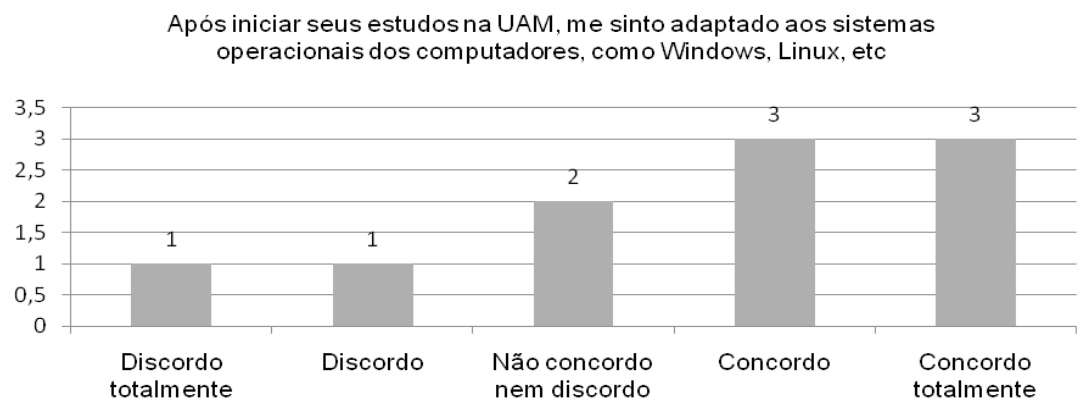

Fonte: dados da pesquisa, 2017

A seguir foi verificou se as aulas na UAM contribuem para uma maior segurança das discentes na navegação na internet (GRÁFICO 8), ao que se percebeu que sete discentes se concordaram com a assertiva; frente a uma que discordou e outra que permaneceu neutra, mostrando que na maioria das pesquisadas o efeito foi positivo.

$\mathrm{Na}$ continuidade, foi questionado se a participação na UAM contribuiu para uma maior familiaridade com o correio eletrônico, os e-mails (GRÁFICO 9) e mais uma vez a maioria das discentes, somando seis respondentes, se manifestaram positivamente frente à assertiva; enquanto que duas discordaram; e novamente uma aluna se manteve neutra. 
RESPONSABILIDADE SOCIAL EMPRESARIAL EM UMA

INSTITUIÇÃO DE ENSINO SUPERIOR PARTICULAR: INSERÇÃO

DA POPULAÇÃO IDOSA ATRAVÉS DA EXTENSÃO

Gráfico 8 - Respostas da discentes da UAM frente a assertiva: Após iniciar seus estudos na UAM, navego com mais segurança na internet

Após iniciar seus estudos na UAM, navego com mais segurança na internet

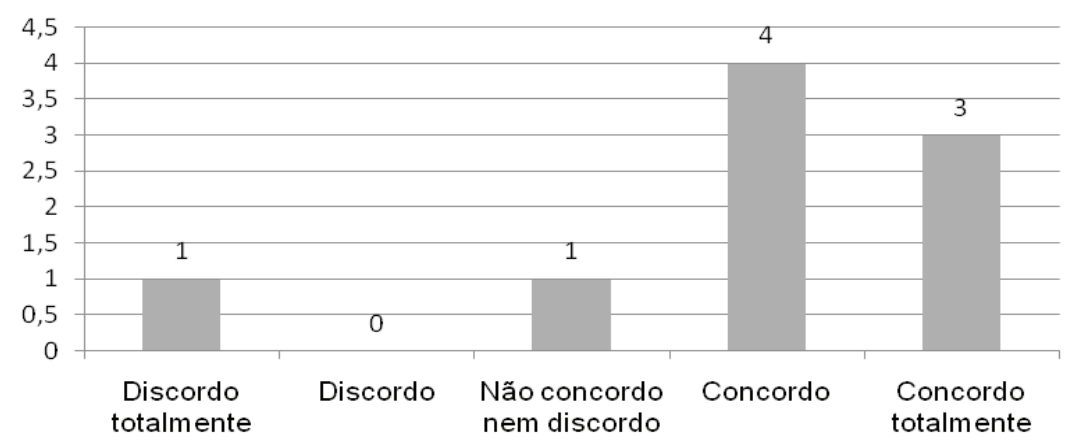

Fonte: dados da pesquisa, 2017

Gráfico 9 - Respostas da discentes da UAM frente a assertiva: Após iniciar seus estudos na UAM, mando e recebo e-mails

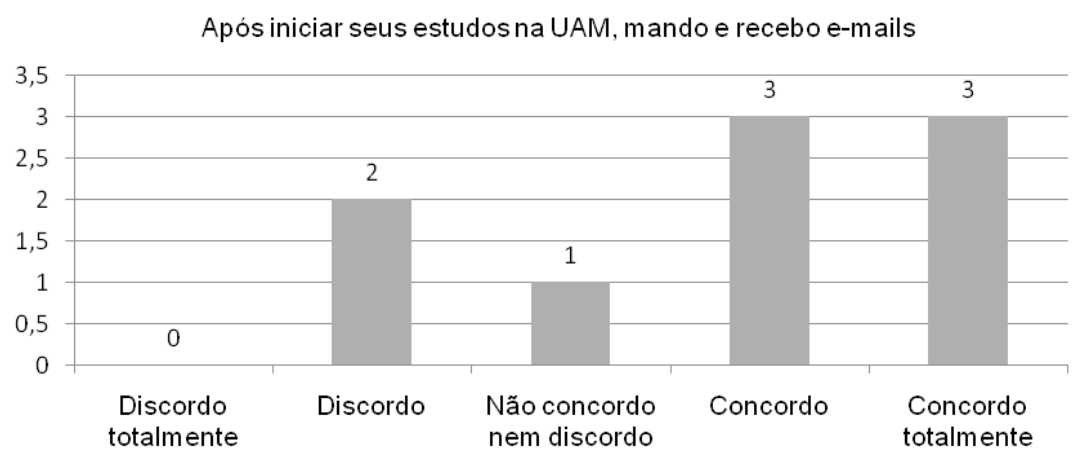

Fonte: dados da pesquisa, 2017

De forma semelhante, se investigou a desenvoltura das pesquisadas com as redes sociais e contribuição da UAM neste quesito, onde se observa no Gráfico 10 que seis pesquisadas manifestaram concordância a assertiva: Após iniciar seus estudos na UAM, me sinto adaptado ao uso das redes sociais; duas alunas se mantiveram neutras; e uma discordou.

ReMAS - Revista Metodista de Administração do Sul, v. 2, N. 2, 2017 
Gráfico 10 - Respostas da discentes da UAM frente a assertiva: Após iniciar seus estudos na UAM, me sinto adaptado ao uso das redes sociais

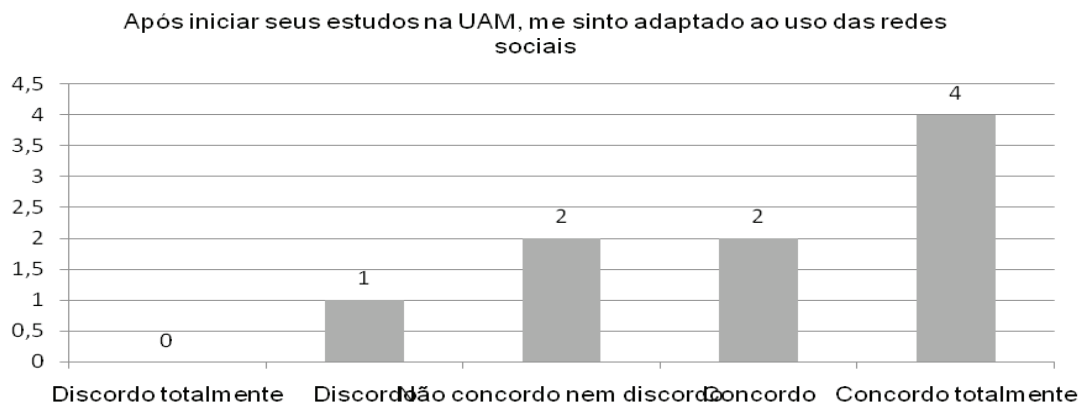

Fonte: dados da pesquisa, 2017

Os autores relatam que $50 \%$ dos idosos que utilizam a Internet melhoram seu contato familiar, social (amigos), comercias (noticias na rede e noticias financeira) e educacionais (pesquisas, filmes e cursos online).

Aqui se traz a contribuição de Neri (2010) que destaca o papel das redes de amigos, que Cardoso et al. (2014) complementam, afirmando que estas podem ser digitais, e uma vez que o idoso se sente motivado ao uso, esta contribui significativamente para a redução do isolamento comum na população idosa, na estimulação mental e no bem estar, propiciando a comunicação com familiares e amigos, aguçando as relações interpessoais e até mesmo promovendo os encontros geracionais pela rede.

Cardoso et al. (2014) vão além em suas observações, destacando que a inclusão digital proporciona ao idoso autonomia e independência, e que isto leva à motivação e a inclusão no mundo virtual, com aumento da autoestima, nas habilidades mentais, autoconfiança, senso de realização e acesso a serviços como caixas eletrônicos e telefonia celular. Entretanto os autores destacam que o mesmo avanço tecnológico que proporciona 
as melhorias citadas, também leva a exclusão digital, quando estes idosos não estão capacitados ao seu uso, citando que há um tripé fundamental para a inclusão digital: tecnologia da Informação, renda e educação e é neste ponto em que a UAM tem papel fundamental, pois o fator renda está atendido, visto que a metade das discentes pesquisadas têm renda superior a 10 salários mínimos, e devem ter acesso a tecnologia, entretanto nem todas sabem utilizá-la, sendo aqui onde as aulas de informática proporcionam os conhecimentos e habilidades necessários para estimular e capacitar as discentes no mundo digital. Uma vez vencidas a resistência e dúvidas iniciais, as internautas sentem-se a vontade para experimentar, alargando a sua rede de contatos e se mantendo ativas digitalmente e assim conquistando os ganhos descritos pelos autores citados.

$\mathrm{Na}$ sequência se verificou, entre as atividades oferecidas pela UAM, aquelas que são mais prazerosas para as discentes pesquisadas, nas quais que se sentem mais adaptadas ou que julgam serem as mais relevantes. Foram oferecidas 16 atividades, algumas focam no aspecto corporal como a ginástica; as atividades aquáticas; movimento; Pilates; alongamento postural e vivências corporais. Outras focam no aspecto mental; como a oficina de memória; reciclagem do pensamento; as terapias complementares e os enfoques (biológico, psicológico, espiritual, histórico e sócio antropológico); e outras são essencialmente lúdicas ou informativas como informática, leitura e literatura, rádio, coral, fotografia, e a história do design, da indumentária e moda sustentável. Entretanto se deve se destacar que não há um limite claro entre uma e outra, pois ao exercitar o corpo, a sensação de bem estar se estende à mente, influenciando os sentimentos e vice-versa.

Nas atividades corporais, as que mais impactaram entre as pesquisadas foram a ginástica, movimento e atividades aquáticas, com os resultados mostrados no Gráfico 11. 
Antes da discussão dos resultados obtidos será feita uma breve caracterização das atividades apontadas pelas discentes com mais prazerosas e relevantes. As oficinas de ginástica e as atividades aquáticas dispensam apresentações, são tradicionais e foram adaptadas à idade das discentes. Já a oficina de movimento consiste em uma atividade física feita frente ao espelho, que estimula o movimento e o equilíbrio dos participantes, é uma atividade mais livre, entre a ginástica e a dança. Se observa que as respondentes não somam dez, pois não há nenhuma das pesquisadas que faça ou tenha feito todas as oficinas. Ainda assim, se observa que a maioria das discentes reconhece as oficinas como muito relevantes, somando pelo menos três discentes entre, pelo menos cinco, pesquisadas.

O Gráfico 11 mostra que, com relação às atividades que focam o aspecto corporal, pelo menos a metade das pesquisadas considerou muito relevante a ginástica, o movimento e as atividades aquáticas, somando três respondentes em cada atividade; por outro lado houve uma discente respectivamente nas modalidades ginástica e movimento que se manteve indiferente; duas pesquisadas que apontaram que a ginástica e as atividades aquáticas respectivamente são nada relevantes; e uma discente que apontou a atividade de movimento como pouco relevante. Aqui há que se considerar também a afinidade das atividades propostas com o temperamento de cada uma das discentes, como foi percebido na conversa informal com as mesmas, pois as atividades consideradas pouco relevantes por algumas, são consideradas muito relevantes por outras, tanto que optaram pela sua prática. 


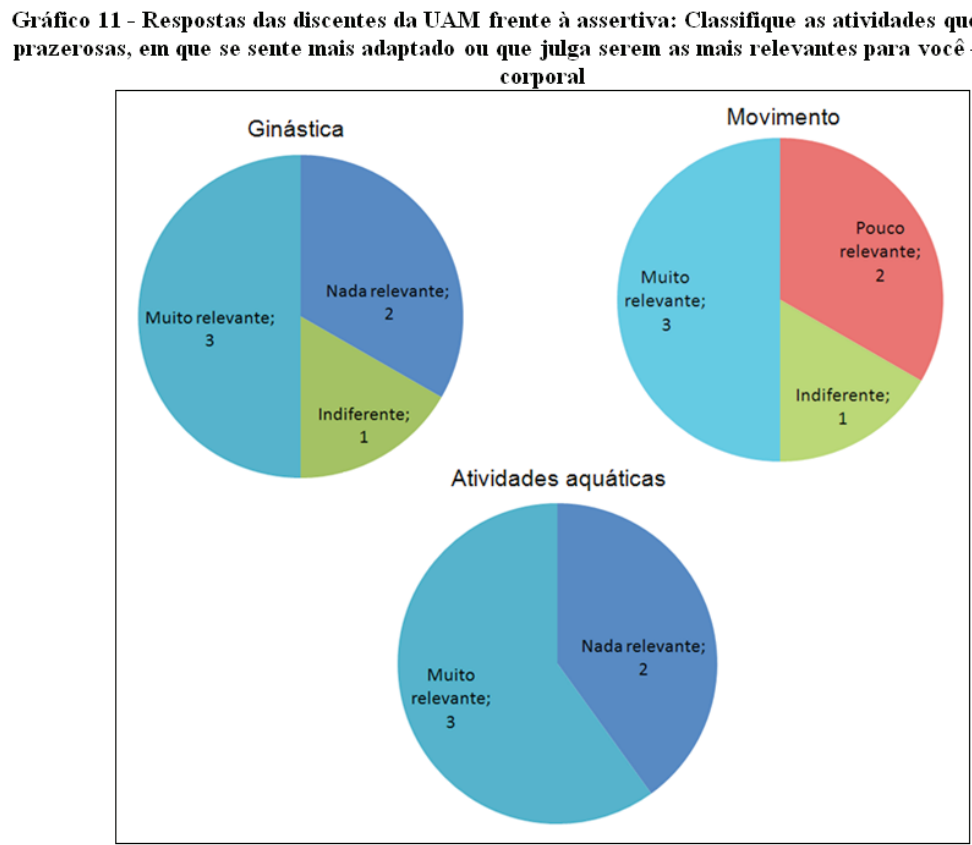

Fonte: dados da pesquisa, 2017

Consolidando estes resultados, se traz a visão de Franchi e Montenegro Junior (2005) que afirmam ser consenso que a atividade física auxilia na autonomia dos idosos, atuando para diminuir suas limitações físicas. Os benefícios dos exercícios físicos para a qualidade de vida são diversos, dentre eles está a preservação da capacidade funcional, que consiste no desempenho para a realização das atividades do cotidiano ou atividades da vida diária. Neri (2012) ressalta que a manutenção da capacidade funcional é um dos índices para averiguação da qualidade de vida entre idosos.

Ainda conforme Neri (2012) a qualidade de vida na maturidade está mais relacionada com um processo de escolhas e situações que o indivíduo passa ao longo da vida, do que a um atributo pessoal ao qual não é possível imprimir mudanças. $\mathrm{O}$ fato das atividades apresentarem alta relevância entre as 
discentes vai ao encontro justamente da percepção de que esse tipo de atividade está relacionada com a qualidade de vida.

Com relação às atividades dirigidas para uma abordagem mental, as três que mais satisfizeram as discentes são a oficina de memória, a reciclagem do pensamento e as oficinas com enfoques biológico, psicológico, espiritual, histórico e sócio antropológico, como expõem o Gráfico 12. As oficinas de memória e reciclagem do pensamento são ministradas por psicóloga e desafiam as discentes a exercitarem a memória e se organizarem mentalmente, respectivamente. Já as oficinas com enfoques biológico, psicológico, espiritual, histórico e sócio antropológico, são ministradas por diferentes professores: advogados, teólogos, fisioterapeutas, entre outros e desafiam os participantes com debates. São postos problemas e os discentes conversam sobre cada um, tomando uma posição. Em alguns temas são realizados até mesmo julgamentos, como por exemplo, no enfoque sócio antropológico, onde foi colocada uma situação onde a mãe criou os filhos sozinha, devido a um pai ausente. Após a morte da mãe, o pai idoso se volta aos filhos e solicita cuidados e os filhos optam por colocá-lo em uma instituição. A partir desta situação é aberto o debate e todos os participantes devem se posicionar, dar a sua opinião, defendendo suas ideias frente ao grupo até que se chegue a um consenso sobre a situação como um todo. Com relação ao enfoque biológico são discutidos temas como o amor e o sexo na terceira idade.

Já o enfoque espiritual aborda as questões referentes ao tema e outras, como a finitude da vida e as perdas, comuns nesta etapa da vida. Se observa que os temas são pertinentes e certamente por isso entusiasmam as discentes, que na grande maioria declararam serem estas atividades muito relevantes ou relevantes, opções que invariavelmente somam respectivamente sete discentes nos enfoques biológico, psicológico, espiritual, histórico e sócio antropológico; cinco alunas na oficina de 
memória; e quatro pesquisadas na reciclagem do pensamento; em cada uma destas atividades uma docente fez a opção de pouco ou nada relevante,como exposto no Gráfico 12.

Estes dados corroboram com os resultados encontrados por Irigaray e Schneider (2008), quando em pesquisa com idosas da UNITI/UFRGS, apontam que os principais motivos das idosas participarem destas atividades é a busca por atualização e novos conhecimentos, aliada a busca por novas amizades, além de um novo sentido de vida, ocupação do tempo livre e lazer. Este resultado também se soma ao aqui encontrado no Gráfico 9 que mostra os resultados sobre a percepção das discentes quanto aos seus relacionamentos, quando a totalidade das discentes concordam, pelo menos parcialmente, que após o ingresso na UAM desenvolveu e manteve mais relacionamentos.

Gráfico 12 - Respostas da discentes da UAM frente a assertiva: Classifique as atividades que são mais prazerosas, em que se sente mais adaptado ou que julga serem as mais relevantes para você - Enfoque mental

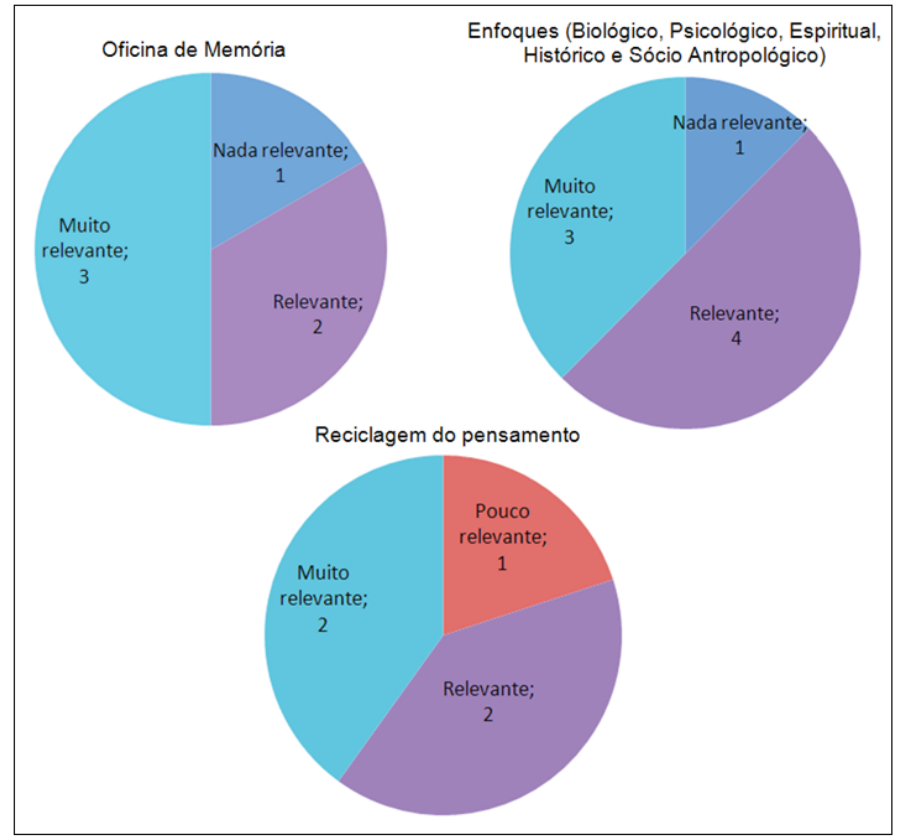

Fonte: dados da pesquisa, 2017

Remas • Revista Metodista de Administração do Sul, v. 2, N. 2, 2017 
É importante trazer a percepção de Neri (2004) que defende que a educação permanente voltada aos idosos está fundamentada no reconhecimento dos valores inerentes a esta faixa etária, a seus direitos e suas oportunidades, sendo assim a educação para estes indivíduos não tem como finalidade divertir ou entreter o idoso, nem de consolidar ou reproduzir papéis desempenhados em outros momentos da vida, mas deve proporcionar meios para que a pessoa, independente da idade cronológica, consiga manter seus níveis normais de funcionamento e de desenvolvimento. De forma concordante, Irigaray e Schneider (2008), ao término de sua pesquisa com idosas da UNITI/UFRGS apontam que nas universidades para a terceira idade os idosos são incentivados a conquistar, manter e preservar a autonomia e a independência, favorecendo a qualidade de vida. Segundo as autoras, neste programa o idoso se sente valorizado e estimulado a conquistar um novo sentido de vida, adquirindo novas informações e ampliando conhecimentos.

Se consideradas as oficinas voltadas a atividades lúdicas e de informação,como informática, leitura e literatura, rádio, coral, fotografia, história do design, da indumentária e moda sustentável, as três que mais são reconhecidas como prazerosas e relevantes pelas pesquisadas foram informática, leitura e literatura e rádio, com a grande maioria reconhecendo que são relevantes ou muito relevantes. Dentre estas a que se destaca é a informática, pois é a atividade que todas pesquisadas participam, sendo que das dez pesquisadas, cinco consideram a informática muito relevante e três consideram relevante; com uma pesquisada apenas na categoria nada relevante e indiferente, como exposto no Gráfico 13. 
Gráfico 13 - Respostas da discentes da UAM frente à assertiva: Classifique as atividades que são mais prazerosas, em que se sente mais adaptado ou que julga serem as mais relevantes para você Enfoque lúdico e informativo

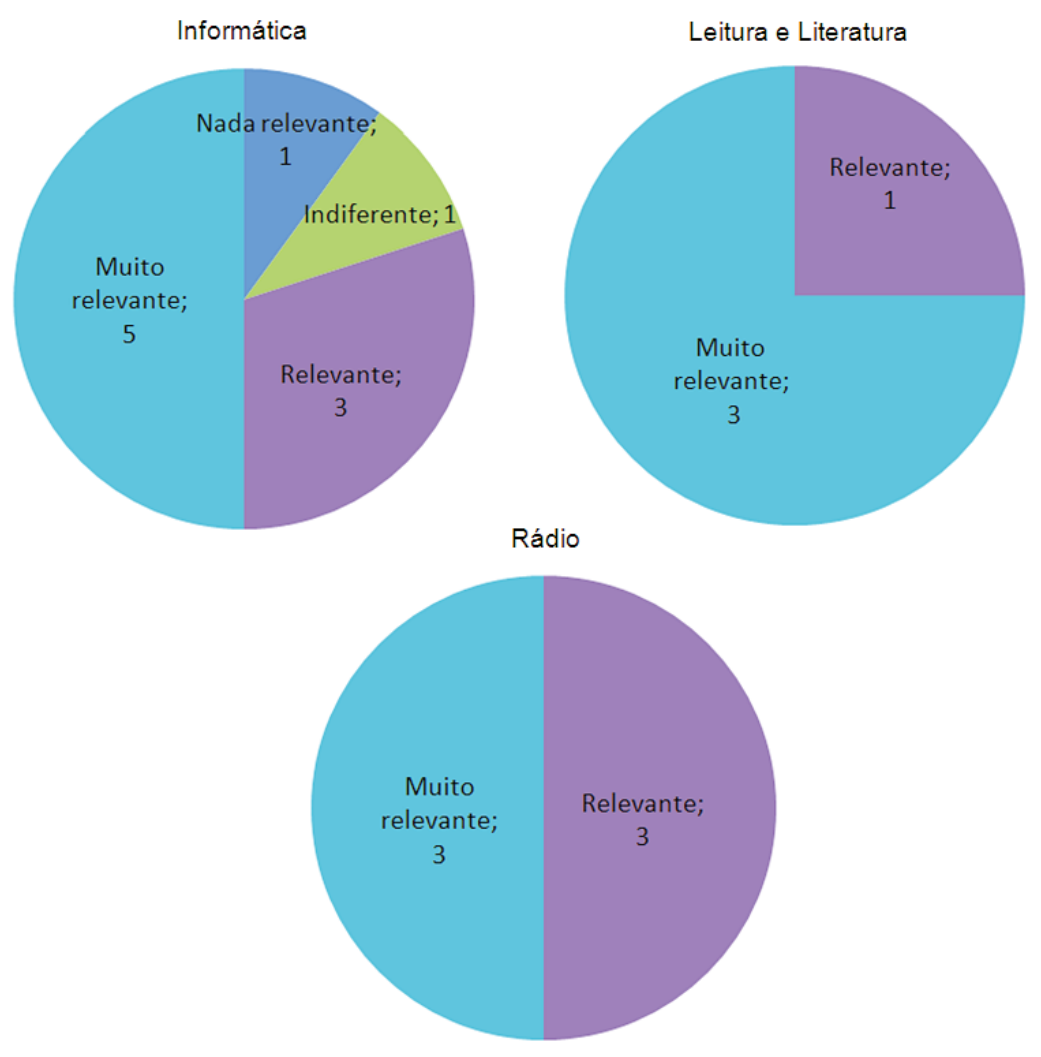

Fonte: dados da pesquisa, 2017

Com relação a atividade de rádio, três pesquisadas a consideraram muito relevante e três consideraram relevante; já a oficina de leitura foi muito relevante para três discentes e relevante para uma aluna.

O resultado sobre a informática apenas corrobora o que já foi exposto anteriormente e vem ao encontro do que defendem 
Cardoso et al. (2014) sobre os benefícios da informática na vida do idoso. É interessante acrescentar a opinião de Vieira e Santarosa (2009), que discutem dados de pesquisa realizada com idosos que frequentam curso de inclusão digital e questionam o porque os idosos que não estão mais inseridos no mercado de trabalho ou envolvidos em atividades de estudo, precisam de um computador. De acordo com as autoras, estas motivações são pessoais e estão estreitamente ligadas a processos de inclusão social, buscando um sentimento de pertencimento à sociedade que o conhecimento da tecnologia pode proporcionar e pela maior quantidade e qualidade de contatos que as ferramentas de comunicação suportadas pela Internet podem oferecer. Como destacam Vieira e Santarosa (2009), no mundo contemporâneo pertencer à sociedade e fazer parte dela implica em se inserir no processo de tecnologização da mesma, sendo que os motivos apontados pelos pesquisados das autoras citadas convergem com os aqui encontrados e que foram expressos nos Gráficos 9, 12 e 8, estão no campo pessoal e dos relacionamentos, vencendo distâncias entre os familiares e a solidão, mostrando que a inclusão social dos idosos passa pela inclusão digital.

Na sequencia a pesquisa buscou identificar entre as atividades oferecidas pela UAM,que focam no aspecto corporal, mental e lúdicas ou informativas, apontadas pelas pesquisadas como mais relevantes, quais as razões que fazem com que aquelas sejam de sua preferência, sendo oferecidas 12 motivações fechadas (Faz com que me sinta incluído; Faz com que desenvolva atividades culturais; Proporciona a aproximação com a cultura; Faz com que eu esteja sempre a par do que acontece no País e no mundo; Me permitem desenvolver habilidades e competências novas; Me permitem aprimorar habilidades e competências que já tinha; Faz com que aumente minha rede social; Faz com que me sinta mais autônomo nas 
atividades cotidianas; Aumentam meu senso de cidadania; Contribuem para o aumento da saúde e qualidade de vida; Contribuem para a prevenção de doenças; e Me sinto bem em frequentar o ambiente universitário) e uma aberta, onde as discentes podiam se manifestar livremente. A semelhança do item anterior, as respostas foram agrupadas, neste item o critério foi a similaridade.

No que diz respeito a inclusão e a inclusão social, se observa que quatro das pesquisadas concordam plenamente que as atividades da UAM as fazem sentir-se incluídas; frente a uma que discorda. No que diz respeito ao aumento da rede social, oito pesquisadas concordam com este aspecto; frente a uma aluna que discorda, conforme exposto no Gráfico 14.

Gráfico 14 - Respostas da discentes da UAM frente à assertiva: Das atividades que você selecionou como relevantes, quais as razões que fazem com que sejam de sua preferência?
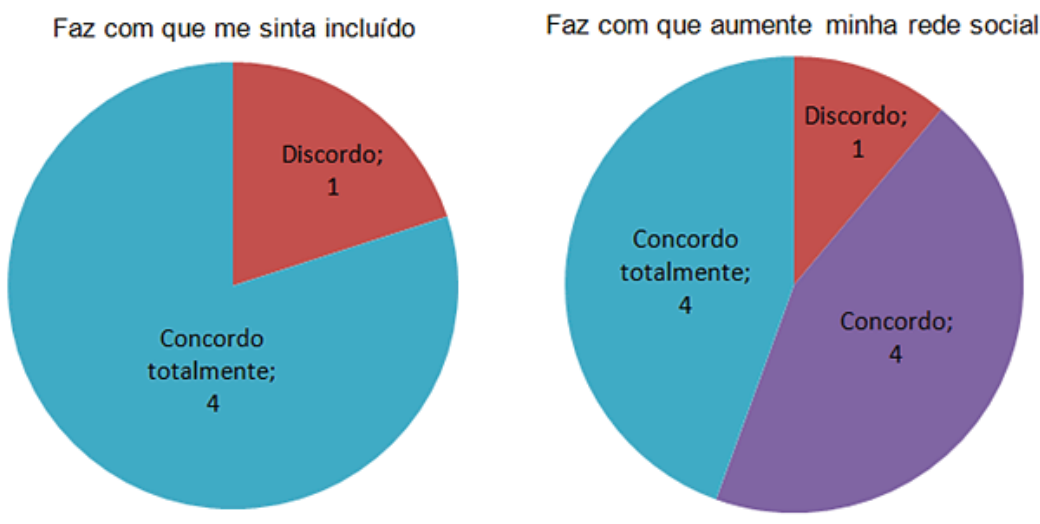

Fonte: dados da pesquisa, 2017

Aqui a autora não irá trazer referências, pois as discussões sobre os itens anteriores trazem em abundância as opiniões de autores que mostram a relevância da inclusão do idoso, 
seja ela digital, aproximando estes indivíduos não só de familiares e amigos, mas do mundo contemporâneo, fortemente informatizado, desde atos cotidianos do mundo virtual, como escolher músicas e filmes, como transações bancárias, compras, entre outros; até a inclusão social no mundo não digital, participando de grupos, viagens, aulas e discussões. A grande movimentação e participação dos idosos da UAM no Facebook do Programa, com a postagem de fotos, mensagens, filmes, curtidas e emoticons, e o fato da maioria das pesquisadas portar um smathphone no momento da entrevista, mostrou que elas estão apropriadas da tecnologia digital e que, além disto, mantêm uma rede social presencial. As fotos das atividades, como a viagem à Museu da Moda em Canela, com 13 participantes e duas professoras; participação em festas juninas, ou declarações com relação ao contentamento com as aulas, sempre acompanhadas de inúmeras curtidas, como por exemplo:

Nossa Turma vivenciou,uma aula para ficar na história....com orientação do Excelente Prof Alexandre Petry.Valeu!!(DISCENTE UAM, 2016).

E até mesmo as manifestações de despedida com relação a colegas que falecem, mostram que os discentes estão ligados por laços de amizade e convivência:

Nossos sentimentos aos familiares e que o querido Dr. João, descanse em paz. (DISCENTE UAM, 2016).

Nosso querido amigo partiu. Estamos tristes. (DISCENTE UAM, 2016).

Estas manifestações atestam que a UAM promove não só a inclusão digital, mas também a inclusão social como um todo, aproximando pessoas com a mesma faixa etária e interesses semelhantes, entre si e com outras, como professores, bolsistas e funcionários da IES, trazendo riqueza de relacionamentos ao cotidiano de todas estas pessoas. 
O próximo grupo de respostas, expressas no Gráfico 15, aborda o aprimoramento e desenvolvimento de competências, ao que cinco discentes concordam totalmente ou concordam que a participação nas atividades da UAM permite o aprimoramento de competências já existentes; frente a uma que discorda. O Gráfico 15 ainda aponta que sete discentes concordam totalmente ou concordam que as atividades da UAM permitiram o desenvolvimento de novas habilidades frente a uma que discorda.

Gráfico 15 - Respostas da discentes da UAM frente à assertiva: Das atividades que você selecionou como relevantes, quais as razões que fazem com que sejam de sua preferência?

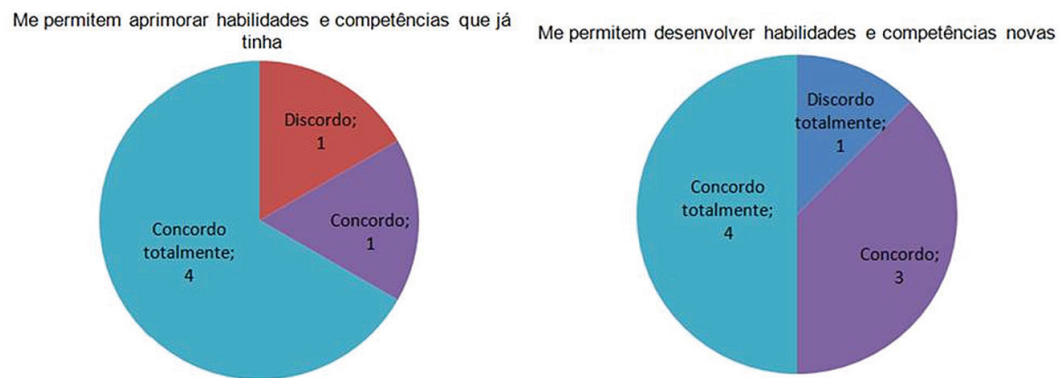

Fonte: dados da pesquisa, 2017

Estes resultados são muito semelhantes aos encontrados por Irigaray e Schneider (2008), na pesquisa com idosas da UNITI/UFRGS, onde frente a questão O que mudou para ti depois que ingressaste na UNITI?, as idosas relatam a aquisição de novos conhecimentos, o prazer em viver com o preenchimento do tempo com atividades prazerosas e a conquista de um novo sentido de vida. Complementando o que foi observado no Gráfico 14, estas idosas relatam que não sentem mais solidão e apresentam melhor auto-estima.

Na sequencia, se apresenta o Gráfico 16 que reúne as respostas das alunas sobre assertivas que dizem respeito à saúde.

ReMAS • Revista Metodista de Administração do Sul, v. 2, N. 2, 2017 
Se observa que, quando estimuladas a apontar entre as atividades oferecidas pela UAM, quais as razões que fazem com que aquelas sejam de sua preferência, seis concordam total ou parcialmente, que estas foram escolhidas porque contribuem para a prevenção de doenças; frente a duas que discordam, total ou parcialmente. Da mesma forma, oito alunas concordam totalmente ou apenas concordam que as atividades foram escolhidas porque contribuem com a saúde e porque melhoram a qualidade de vida; contra uma que discorda. A última assertiva abordada, a autonomia com relação as atividades cotidianas, conta com a concordância parcial ou total de nove discentes, frente a duas, uma indiferente e outra que discorda totalmente.

Gráfico 16 - Respostas da discentes da UAM frente à assertiva: Das atividades que você selecionou como relevantes, quais as razões que fazem com que sejam de sua preferência?

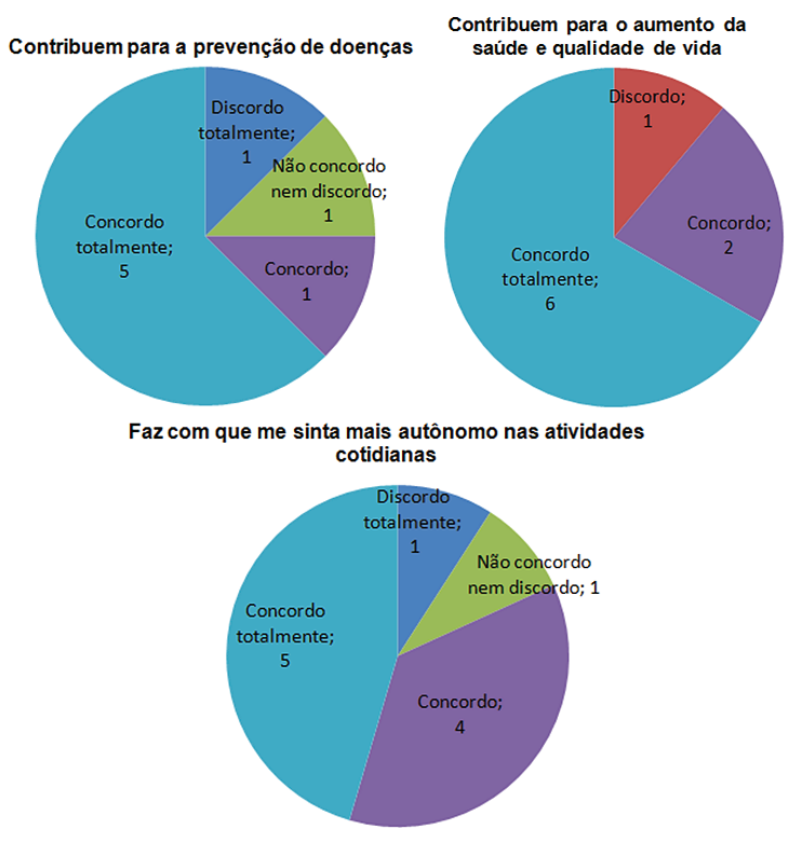

Fonte: danvo un proyusu, <vs, 
Sobre o tema, Irigaray e Schneider (2008), afirmam, de forma concordante com o encontrado, que as idosas pesquisadas relatam de uma forma geral uma melhoria nas questões de saúde enquanto participantes das atividades em grupo da UNITI/UFRGS.

As questões intelectuais não foram esquecidas, e estão reunidas no Gráfico 17, que retrata a resposta das pesquisadas com relação as razões que fazem com que as atividades relacionadas a este foco sejam de sua preferência, seis apontam que concordam totalmente e concordam, que a UAM estimula as atividades culturais; frente a uma que discorda. Sobre fato das atividades da UAM permitirem às participantes estarem atualizadas com o que acontece no País e no mundo, cinco discentes pelo menos concordam; e uma discorda. Se considerado o censo de cidadania, seis discentes pelo menos concordam que há um aumento neste quesito; uma aluna é indiferente; e outra discorda totalmente da assertiva.

A assertiva Proporciona a aproximação com a cultura não está representada no Gráfico 17, pois a totalidade das pesquisadas respondeu que concorda totalmente com a afirmativa. As questões culturais e de informação já foram abordadas de alguma forma nos itens antecedentes, então aqui se fará um detalhe sobre a cidadania. Roratto e Vieira (2011) trazem que a cidadania deve ser entendida com a possibilidade de defesa dos seus direitos, poder reivindicar e ser ouvido e ter o respeito às posições individuais, e particularmente em assuntos de interesse de cada um. Desta forma a cidadania permite desfrutar de uma vida digna, com saúde e qualidade de vida. Entretanto com o envelhecimento estes direitos vão sendo gradualmente negados aos cidadãos, seja por questões físicas ou psicológicas, seja pela diminuição da participação das pessoas desta faixa etária no mercado de trabalho, através da aposentadoria ou desemprego, ou ainda, pela diminuição 
Gráfico 17 - Respostas da discentes da UAM frente à assertiva: Das atividades que você selecionou como relevantes, quais as razões que fazem com que sejam de sua preferência?
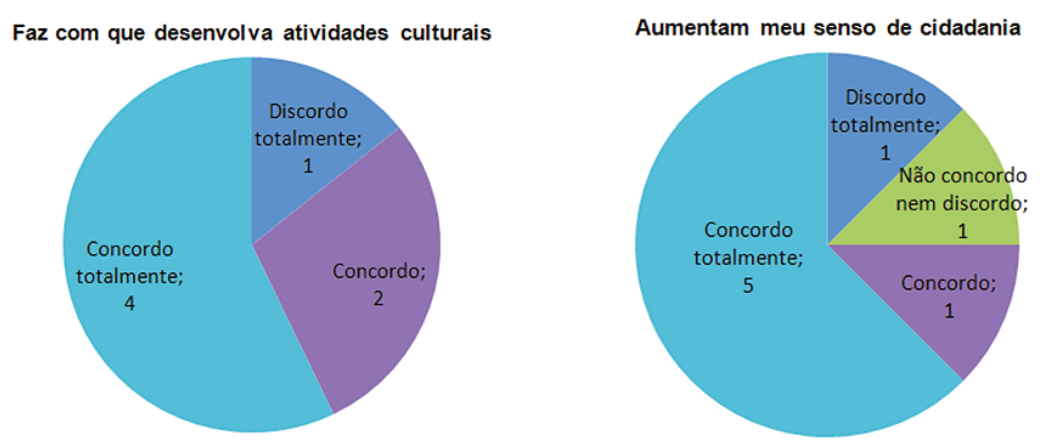

Faz com que eu esteja sempre a par do que acontece no País e no mundo

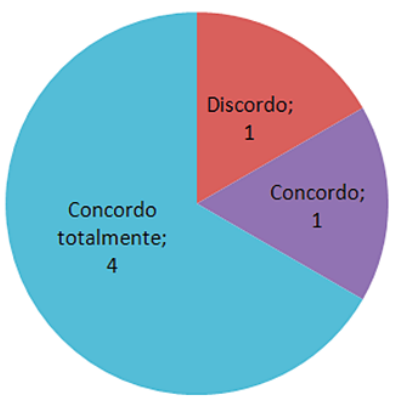

Fonte: dados da pesquisa, 2017

na participação na vida social. Assim as pessoas da terceira idade perdem gradualmente a sua identidade, já não são mais os provedores do lar, não são requisitados no mercado de trabalho e não são os educadores de seus filhos, sentindo-se perdidos em uma sociedade que os exclui e os ignora enquanto cidadãos.

Neste sentido a participação em processos educativos ou pedagógicos, que qualificam as relações sociais e desenvolvem comportamentos e pensamentos emancipatórios, permitem o resgate da cidadania, que é exatamente o que se percebe pelas respostas das discentes pesquisadas. 
Ao se encaminhar para o final da pesquisa, se apresenta o Gráfico 18, onde estão representadas as respostas a alternativa Me sinto bem em frequentar o ambiente universitário, onde se observa que oito discentes revelam que concordam plenamente e duas concordam, mostrando a satisfação da convivência em um meio onde o idos se identifica, pois não se sente excluído, partilha amizades e enfrenta desafios e tem oportunidades de aprendizagem.

No fechamento do presente capítulo, a autora conscientemente foge do estabelecido e faz uma citação, de Alencar (2013, p. 25) que afirma que "em qualquer idade é sempre tempo de viver, de expressar a singularidade que permeia cada ser humano, que para cada um tem um começo e fim próprio", e é assim que a pesquisadora percebe as discentes da UAM, indivíduos que buscam manter a autonomia e a independência, se afastando dos estigmas do envelhecimento, em geral associado à perda, doença e incapacidade.

Gráfico 18 - Respostas da discentes da UAM frente à assertiva: Das atividades que você selecionou como relevantes, quais as razões que fazem com que sejam de sua preferência?

\section{Me sinto bem em frequentar o ambiente universitário}

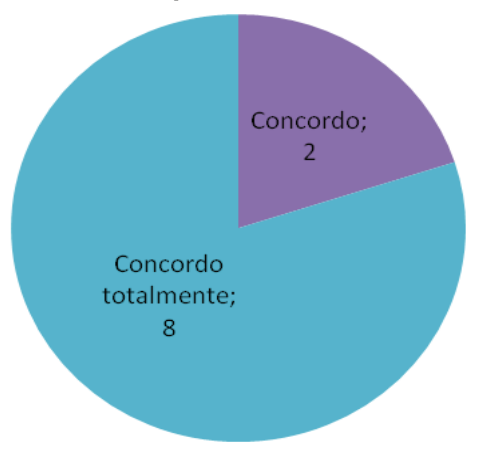

Fonte: dados da pesquisa, 2017 
Aqui é necessário lembrar o Estatuto do Idoso que determina o apoio na construção de Universidades Abertas para Terceira Idade, buscando estimular possibilidades individuais e coletivas, com a formação de consciência crítica, autonomia, reforço de relações sociais que permitam lazer, atividades física e mentais para os indivíduos desta faixa etária. (BRASIL, 2003).

Roratto e Vieira (2011) destacam que os indivíduos ao entraram na terceira idade, têm suas forças (física, social, política) diminuídas e de forma alguma estes indivíduos devem ser abandonados ou excluídos, é justamente neste momento que a sociedade organizada deve coordenar ações buscando manter ou reconstruir a possibilidade das pessoas mais velhas terem seus direitos garantidos e serem ouvidos em suas questões e opiniões.

\section{CONSIDERAÇÕES FINAIS}

Esta pesquisa foi realizada no Centro Universitário Metodista IPA, instituição de ensino superior na cidade de Porto Alegre, no estado do Rio Grande do Sul, junto ao Programa de Extensão Universidade do Adulto Maior, sendo autorizada com Certificado de Apresentação para Apreciação Ética (CAAE) número 67784316.1.0000.5308.

Com relação a inserção das questões de responsabilidade social empresarial na gestão da IES pesquisada, concluiu-se que o Programa Universidade Adulto Maior possui significativa influência do movimento metodista, que permeia toda a gestão da IES pesquisada. Também se percebeu que a Coordenadoria de Extensão é responsável pelos programas de responsabilidade social da IES e que os mesmo são custeados pelo IPA, sem qualquer participação externa, mas com apoio interno, o que configura a responsabilidade social empresarial da instituição.

Quanto a contribuição do programa para alcançar os objetivos do Centro Universitário Metodista, bem como para 
o desenvolvimento da população atendida pelo programa, se observou que a UAM contribui com os objetivos da IES, que são o fomentar a ciência e o conhecimento, visto que a convivência entre geração proporcionada pela presença dos discentes da UAM no ambiente acadêmico auxilia na aprendizagem de estagiários, alunos de outros cursos e dos próprios funcionários da IES. Com relação aos ganhos dos alunos da UAM, foram destacados aumento da qualidade de vida; ganhos na parte cognitiva; mudança de perspectiva de vida; aquisição de informação; aumento da autoestima; e ter voz e ser ouvido no grupo, além do contato com novas tecnologias, que diminuem a distância entre essa faixa da população e as demais gerações.

Sobre os impactos da Universidade Adulto Maior (UAM) na qualidade de vida dos participantes, primeiramente se traçou um perfil dos discentes, ainda que a amostra fosse restrita, se observou que o grupo pesquisado se constitui de mulheres, com faixa etária de 70 e 74 anos, moradoras da zona Oeste da Capital, com curso superior completo e renda acima dos 20 salários mínimos, que representa um valor de $\mathrm{R} \$ 15.760,01$ ou mais e de acordo com o salário mínimo vigente à época da pesquisa, que tomaram conhecimento do Programa Universidade Adulto Maior através de amigos e familiares.Este perfil sócio econômico está de acordo com os traçados para outros programas semelhantes da Região Sul do País.

Se constatou que a participação na UAM trouxe às pesquisadas mais relacionamentos sociais, uma maior desenvoltura a com a tecnologia, em particular com os computadores e com a internet. Considerando as diversas atividades oferecidas, entre aquelas com um enfoque corporal, as que mais agradam as discentes são a ginástica, a oficina de movimento e as atividades aquáticas. Já entre as atividades com enfoque mental foram apontadas pelas pesquisadas a oficina de memória, a reciclagem do pensamento e as oficinas com enfoques bioló-

ReMas - Revista Metodista de Administração do Sul, v. 2, N. 2, 2017 
gico, psicológico, espiritual, histórico e sócio antropológico, sendo esta última um sucesso entre os alunos, com se percebeu pelas postagens no Facebook da UAM. Se consideradas as oficinas voltadas a atividades lúdicas e de informação as três que mais são reconhecidas como prazerosas e relevantes pelas pesquisadas foram a informática, a leitura e literatura e o rádio. Estas atividades resultam, na opinião das pesquisadas, em um sentimento de inclusão, de aprimoramento e desenvolvimento de habilidades, que contribuem com a saúde, com a prevenção de doenças e na qualidade de vida e na autonomia com as atividades cotidianas. Estas oficinas também fomentam as atividades sociais, culturais e o sentimento de cidadania. Finalmente as pesquisadas são unânimes com relação a sensação de bem estar no ambiente universitário.

No que aos desafios para a responsabilidade social empresarial em uma instituição de ensino superior particular a partir da inserção da população idosa através da extensão conclui-se que a instituição pesquisada atende as questões de responsabilidade social, através do Programa de Extensão Universidade Adulto Maior, sendo precursora dessa modalidade de responsabilidade social empresarial entre as instituições de ensino superior particulares. Os discentes pesquisados atestaram a importância do Programa na contribuição para a qualidade de vida.

Como fator limitador da pesquisa a autora aponta a amostra restrita, de apenas dez respondentes, ao qual dispunha para aplicação da pesquisa.

\section{REFERÊNCIAS}

ALESSIO, Rosemeri. Responsabilidade Social das empresas no Brasil: reprodução de Postura ou novos rumos? Porto Alegre: EDIPUCRS, 2008.

BOLAN, Valmor; MOTTA, Márcia Vieira da. Responsabilidade Social no Ensino Superior. Revista de Educação, Itatiba, v. 10, p. 204-2010, 2007. 
RESPONSABILIDADE SOCIAL EMPRESARIAL EM UMA

INSTITUIÇÃO DE ENSINO SUPERIOR PARTICULAR: INSERÇÃO

DA POPULAÇÃO IDOSA ATRAVÉS DA EXTENSÃO

Disponível em: <http://www.sare.anhanguera.com/index.php/reduc/article/ view/229>. Acesso em: 10 jun. 2016.

BRASIL, Leino 10.741 , de $1^{\text {o }}$ de outubro de 2003. Dispõe sobre o Estatuto do Idoso e dá outras providências. Diário Oficial [da] República Federativa do Brasil. Poder Executivo, Brasília, DF, 1ํ de outubro de 2003. Disponível em: http://www.planalto.gov.br/ccivil_03/leis/2003/L10.741.htm. Acesso em: 10 out. 2015.

BRASIL, Leino 9.394, de 20 de dezembro de 1996. Estabelece as diretrizes e bases da educação nacional. Diário Oficial [da] República Federativa do Brasil. Poder Executivo, Brasília, DF, 20 de dezembro de 1996. Disponível em: <http://www.planalto.gov.br/ccivil_03/Leis/L9394.htm>. Acesso em: 2 nov. 2015.

CAMARANO,Ana Amélia.Novo regime demográfico: uma nova relação entre população e desenvolvimento?Rio de Janeiro: IPEA, 2014. Disponível em: <http://www.ipea.gov.br/portal/index.php?option=com _ content\&view=article\&id=23975>. Acesso em: 11 nov. 2016.

CARDOSO Raul G. S; STEFANELLO, Débora R.; SOARES, Karla V. B. de Castro; ALMEIDA, Will R. M.Os benefícios da informática na vida doidoso.2014.Disponível em:<http://siaiap32.univali.br/seer/index.php/acotb/ article/download/5338/2795. > Acesso em: 10 abr. 2017.

CENTRO UNIVERSITÁRIO METODISTA DO IPA. [Apresentação daPró-Reitoria de Extensão e Ação Comunitária]. Disponível em: <http://www. metodistadosul.edu.br/extensao/pro_reitoria.php?opcao=1\&codigo=23877 >. Acesso em: 04 nov. 2016.

CENTRO UNIVERSITÁRIO METODISTA DO IPA. [Institucional]. Disponível em: < http://ipametodista.edu.br/institucional/centro-universitario/>. Acesso em: 15jun. 2017.

CERVO, Amado Luiz; BERVIAN, Pedro Alcino. Metodologia Científica. 5.ed. São Paulo: Prentice Hall, 2002.

COLOMBO, Sonia Simões. Gestão universitária: os caminhos para a excelência. Porto Alegre: Penso, 2013.

FERREIRA, Luciana Fátima de Araújo Gonçalves. Formas de inclusão da terceira idade proporcionadas pela educação a distância. In:X CONGRESSO BRASILEIRO DE ENSINO SUPERIOR A DISTÂNCIA (ESUD), 2013, Belém. Trabalhos 2013... Belém: UNIREDE, 2013. Disponível em: http://www.aedi. ufpa.br/esud/trabalhos/poster/AT2/114162.pdf. Acesso em: 10 out. 2015.

ReMas - Revista Metodista de Administração do Sul, v. 2, N. 2, 2017 
FERRELL, O. C.; FRAEDRICH, John P.; FERRELL, Linda.Ética empresarial: dilemas, tomadas de decisões e casos. São Paulo: Reischmann\& Affonso, 2001.

FONSECA, João José Saraiva da.Metodologia da pesquisa científica. Fortaleza: UEC, 2002. Disponível em: <http://www.ia.ufrrj.br/ppgea/conteudo/ conteudo-2012-1/1SF/Sandra/apostilaMetodologia.pdf >. Acesso em: 10 jun. 2015.

IBGE. Mudança Demográfica no Brasil no Início do Século XXI. Subsídios para as projeções da população. Rio de Janeiro: [s.n.], 2015. Disponível em: < http://loja.ibge.gov.br/mudanca-demografica-no-brasil-no-inicio-do-seculo-xxi-subsidios-para-as-projecoes-da-populac-o.html. >. Acesso em: 10 ago. 2016

IBGE. Síntese de indicadores sociais: uma análise das condições de vida da população brasileira. Rio de Janeiro: [s.n.], 2015. Disponível em: http://biblioteca.ibge.gov.br/visualizacao/livros/liv95011.pdf >. Acesso em: 10 ago. 2016

INEP. SINAES.Brasília: INEP, 2016. Disponível em: <http://portal.inep.gov. br/superior-sinaes>. Acesso em: 04 nov. 2015.

INEP. Sinopse Estatística da Educação Superior. Brasília: INEP, 2016. Disponível em: <http://portal.inep.gov.br/superior-censosuperior-sinopse>. Acesso em: 12.nov.2016.

IPEA. Terceira Idade e Esperança de Vida: o Brasil no cenário internacional. Brasília: [s.n.], 2008

IRIGARAY, Tatiana Quarti; SCHNEIDER, Rodolfo Herberto. Participação de idosas em uma universidade da terceira idade: motivos e mudanças ocorridas. Psic.: Teor. e Pesq., Brasília, v. 24, n. 2, p. 211-216, June 2008 . Disponível em: <http://www.scielo.br/scielo.php?script=sci_arttext\&pid=S0102-37722008000200011\&lng=en\&nrm=iso>. Acesso em: 20 nov. 2016.

KLEIN, AmarolindaZanela; SILVA, Lisiane Vasconcellos da; MACHADO, Lisiane; AZEVEDO, Debora.Metodologia de pesquisa em administração: Uma abordagem prática. São Paulo: Atlas, 2015.

MELO NETO, Francisco Paulo de; FROES, César. Responsabilidade Social e cidadania empresarial: a administração do terceiro setor. 2.ed. 2. reimp. Rio de Janeiro: Qualitymark, 2005.

NASCIMENTO, Marcelo de Maio. Programa Vida Ativa-PROEXT (20152016). Petrolina - PE: Fundação Universidade Federal do Vale do São Francisco (UNIVASF), 2014. Disponível em: http://proex.univasf.edu.br/ wp-content/uploads/2014/10/UNATI-Universidade-Aberta-da-Terceira-Idade. pdf. Acesso em: 10 out. 2015. 
RESPONSABILIDADE SOCIAL EMPRESARIAL EM UMA

INSTITUIÇÃO DE ENSINO SUPERIOR PARTICULAR: INSERÇÃO

DA POPULAÇÃO IDOSA ATRAVÉS DA EXTENSÃO

NERI, Anita Liberalesso. Qualidade de vida e idade madura. Campinas, SP: Papirus, 2012.

PEIXOTO, Clarice Ehlers. De volta às aulas ou de como ser estudanteaos 60 anos, pp. 41-74. In RP Veras (org.). Terceira idade: desafios para o terceiro milênio. Rio de Janeiro: RelumeDumará-UERJ-UnATI, 1997.

PORTO ALEGRE. Prefeitura Municipal. Observapoa. População Idosa de Porto Alegre: informação demográfica e socioeconômica. Porto Alegre, 2015. Disponível em: <http://lproweb.procempa.com.br/pmpa/prefpoa/observatorio/ usu_doc/informacao_demografica_e_socioeconomica-populacao_idosa02. pdf>. Acesso em:10 abr. 2016.

RORATTO, João Manoel; VIEIRA, Maria Margareth Garcia. A universidade e a reconstrução da cidadania na terceira idade. Fórum da Gestão do Ensino Superior nos Países e Regiões de Língua Portuguesa. A universidade e a reconstrução da cidadania na terceira idade. 2011. (Congresso). Disponível em: <http://www.forumgestaoensinosuperior2011.ul.pt/docs_documentos/15/ paineis/04/jmr_mmgc.pdf>. Acesso em 10 set. 2016.

TERRA, Newton Luiz. Envelhecendo com qualidade de vida. Porto Alegre: Edipucrs, 2001.

VERAS, Renato Peixoto; CALDAS, Célia Pereira. Promovendo a saúde e a cidadania do idoso: o movimento das universidades da terceira idade. Ciênc. saúde coletiva [online]. 2004, vol.9, n.2, p. 423-432. Disponível em: http:// www.scielo.br/pdf/csc/v9n2/20396.pdf. Acesso em: 10 out. 2015

VIEIRA, Sonia. Como elaborar questionários. São Paulo: Atlas, 2009. 


\section{PARECER CONSUBSTANCIADO DO CEP}

\section{DADOS DO PROJETO DE PESQUISA}

Título da Pesquisa: RESPONSABILIDADE SOCIAL EMPRESARIAL EM UMA INSTITUIÇÃO DE ENSINO SUPERIOR PARTICULAR:

inserção da população idosa através da extensão

Pesquisador: ANDREA SANDER

Área Temática:

Versão: 2

CAAE: 67784316.1 .0000 .5308

Instituição Proponente: Centro Universitário Metodista IPA/ Federação de Faculdades Metodista do

Patrocinador Principal: Financiamento Próprio

\section{DADOS DO PARECER}

Número do Parecer: 2.083.364

Apresentação do Projeto:

Projeto de pesquisa do curso de administração intitulado "RESPONSABILIDA.DE SOCIAL EMPRESARIAL EM UMA INSTITUIÇÃO DE ENSINO SUPERIOR PARTICULAR: inserção da população idosa através da extensão" da acadêmica Isadora Ciarini Ribeiro orientada pela professora Mestre Andrea Sander.

\section{Objetivo da Pesquisa:}

Objetivo Primário:

Verificar quais os desafios para a responsabilidade social empresarial em uma Instituição de ensino superior particular a partir da inserção da

população idosa através da extensão.

Objetivo Secundário:

a) Identificar como estão inseridas as questões de responsabilidade social empresarial na gestão da IES pesquisada;b) Verificar a contribuição do programa para alcançar objetivos da IES pesquisada, bem como para o desenvolvimento da população atendida pelo programa;c) Identificar os impactos da Universidade Adulto Maior (UAM) na qualidade de vida dos participantes.

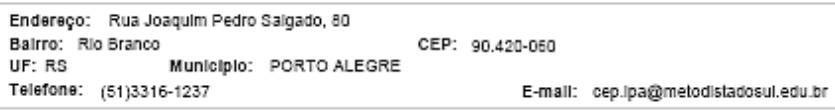

